\title{
ENTRE A TERRA E A ÁGUA: A PESCA E O CONHECIMENTO ETNOICTIOLÓGICO DOS PESCADORES ARTESANAIS
}

\section{BETWEEN LAND AND WATER: FISHING AND ETHNO-CYTOLOGICAL KNOWLEDGE OF ARTISANAL FISHERMEN}

\author{
Joanice Costa AMORIM ${ }^{1 *}$; Karina Neoob Carvalho CASTRO²; Romildo Ribeiro SOARES ${ }^{3}$; Roseli Farias Melo de \\ BARROS $^{4}$; Ivanilza Moreira de ANDRADE 5
}

${ }^{1}$ E. E. Gervásio dos Santos Costa, Rua Minas Gerais, 974, Centro, CEP: 78875-000, Gaúcha do Norte - Mato Grosso, Brasil. ${ }^{2}$ Embrapa Meio-Norte, Av. Duque de Caxias, 5.650, Buenos Aires, CEP: 64006220, Parnaíba - Piauí, Brasil; ${ }^{3,4}$ Departamento de Biologia, Universidade Federal do Piauí, Av. Universitária, s/n, Bairro Ininga, CEP 64049-550, Teresina - Piauí, Brasil. ${ }^{5}$ Programa de Pós-Graduação em Desenvolvimento e Meio-Ambiente (MDMA/UFPI), Núcleo de Referências em Ciências Ambientais do Trópico Ecotonal do Nordeste (TROPEN), Av. Universitária, 1310, CEP 64049-550, Teresina - Piauí, Brasil. *contato: e-mail: joanicee_amorim@ hotmail.com

RESUMO: A pesca artesanal tem como característica principal o uso da mão de obra familiar, embarcações de pequeno porte e apetrechos tradicionais e rudimentares para a captura de peixes. Objetivou-se investigar o conhecimento etnoictiológico dos pescadores artesanais da colônia de pescadores Z-9 residentes no município de Castelo do Piauí, Piauí. Levantou-se dados qualitativos e quantitativos com 55 informantes, por meio de entrevista semiestruturada. Os dados foram compilados e analisados utilizando os programas estatísticos Excel, BioEstat 5.0 e EstimateSWin 9.10. Para análise dos dados calcularam-se o Valor de Uso (VU), Fator de Consenso dos Informantes (FCI), Importância Relativa (IR), além de índices de diversidade, tais como Shannon-Wiener, Simpson e rarefação. Registrou-se 49 espécies, 33 gêneros e 20 famílias de peixes, distribuídas em três categorias de uso: alimentícia, comercial e medicinal. ProchiloduslacustrisSteindaches, 1907 (crumatá) apresentou maior valor de uso geral e potencial (VU geral = 2,02; VU potencial $=1,85$ ), seguida das espécies LeporinusfridericiBloch, 1974 (piau-de-coco) e SchizodondissimilisGarman, 1890 (piau-de-vara), ambas com VU geral =1,78 e VU atual=1,75. Dentre as doenças citadas, a categoria com maior valor de Fator de Consenso dos informantes (FCI) foi a de Lesões, envenenamentos e algumas outras consequências de causas externas $(\mathrm{FCI}=1)$, seguida de doenças do aparelho respiratório $(\mathrm{FCI}=0,93)$. De acordo com o índice de importância relativa (IR), as espécies mais versáteis foram PotamotrygonsignataGarman, 1913 (arraia, IR = 2,00), seguida de Hopliasaff. malabaricusBloch, 1794 (traíra, IR = 1,82) e P. lacustris(crumatá, IR = 1,39). A atividade pesqueira no município de Castelo do Piauí é realizada no rio Poti, os pontos de pesca citados foram: Poço Amarelo, rio Cais, Cânion do Poti e Mesa de Pedra, e a distância percorrida para a pesca pode ser superior a $60 \mathrm{~km}$. Foram registrados seis tipos de apetrechos de pesca: anzol de linha, anzol de vara, engancho, groseira, rede de emalhe e tarrafa. Algumas espécies, tais como P. lacustris, foram citadas como "reimosas". Deste modo, pode-se dizer que os pescadores artesanais são detentores de conhecimento empírico da atividade pesqueira.

Palavras-chave: Apetrechos de pesca, Etnoictiologia, peixes medicinais, reima, tabus alimentares.

ABSTRACT: Artisan fishing is characterized mainly by the use of family labor, small fishing craft and simple, traditional equipment for catching fish. The objective of this study was to investigate the ethnoicthyological knowledge of the artisan fishermen of the Z-9 fishing colony in the municipality of Castelo do Piauí, Piauí state, Brazil. Qualitative and quantitative data were collected from 55 informants using semi-structured interviews. The data were compiled and analysed using the statistical programs Excel, BioEstat 5.0 and EstimateS Win 9.10. Data analysis included the calculation of Use Value (VU), Informant Consensus Factor (FCI), Relative Importance (IR) and diversity indices such as Shannon-Wiener, Simpson and rarefaction. 49 fish species were cited by informants, in 33 genera and 20 families, divided into food, commercial and medicinal use categories. ProchiloduslacustrisSteindaches, 1907 (crumatá) had the highest general and potential use values (general VU $=2.02$; potential $\mathrm{VU}=1.85$ ), followed by the species Leporinusfriderici, Bloch, 1974 (piau-de-coco) and SchizodondissimilisGarman, 1890 (piau-de-vara), both with general $\mathrm{VU}=1.78$ and actual $\mathrm{VU}=1.75$. Among the health disorders cited, the category with the highest Informant Consensus Factor (FCI) was that of injuries, poisonings and other conditions due to external causes (FCI $=1$ ), followed by diseases of the respiratory system $(\mathrm{FCI}=0.93)$. According to the Relative Importance index (IR), the most versatile species were Potamotrygon signata Garman, 1913 (arraia, IR = 2.00), followed by Hopliasaff. malabaricus Bloch, 1794 (traíra, IR = 1.82 ) and $P$. lacustris (crumatá, IR = 1.39). Fishing in the municipality of Castelo do Piauí takes place in the Poti river and the fishing localities cited were PoçoAmarelo, Cais river, Cânion do Poti and Mesa de Pedra; the distance covered for a fishing trip can be over $60 \mathrm{~km}$. Six types of fishing tackle were recorded: line hook, pole hook, hook, coarse, gill net and tarrafa. Some species, such as P. lacustris, were cited as "harmful". It may thus be concluded that artisan fishermen are holders of empirical knowledge derived from fishing and the use of fish.

Keywords: Fishing tools, Ethnoicthyology, food taboos, harmful effects, medicinal fish. 
Amorin et al. Entre a terra e a água: a pesca e o conhecimento etnoictiológico dos pescadores artesanais. Ethnoscientia 4, 2019. DOI: 10.22276/ethnoscientia.v4i1.240

\section{INTRODUÇÃO}

Os peixes constituem o grupo mais diversificado entre os vertebrados e sua diversidade está em torno de 35.000 espécies conhecidas (FRICKE et al., 2019), tendo a Região Neotropical uma das mais diversificadas faunas de peixes de água doce do mundo (BUCKUP et al., 2007), com 8.000 espécies (REIS et al., 2003, 2016). Embora o Brasil também apresente diversidade de peixes de água doce, cerca de 2.500 espécies (BUCKUP et al., 2007), muitas áreas precisam ser estudadas para se estimar a real diversidade existente.

O Brasil possui uma grande rede de cursos d'água, detendo as maiores redes hidrográficas do mundo (GALVES et al., 2009), sendo a pesca artesanal praticada por muitas comunidades ribeirinhas. Esta atividade é definida como aquela em que o pescador captura o pescado utilizando ferramentas simples (DIEGUES, 1998) que causa menor impacto ambiental por seus métodos de captura que utilizam instrumentos tradicionais e de grande importância para o meio cultural (BRANDÃO; SILVA, 2008). Caracteriza-se por ser realizada em pequena escala, com uso de embarcações de pequeno porte e por $90 \%$ da mão de obra desempenhada por pescadores (FAO, 2010, 2012).

A pesca artesanal é uma cultura do cotidiano de povos ribeirinhos e litorâneos responsável pela maior parte do produto pesqueiro consumido pelos humanos com grande variedade de espécies (SILVANO, 2004) que favorece a criação de empregos, redução do êxodo rural, equilíbrio da balança de pagamentos, segurança alimentar, reconhecimento de recursos aquáticos e valorização do ecoturismo (FIDALGA et al., 2014). Embora haja fatores que comprometem a continuação desta atividade, tais como: poluição dos rios, assoreamento e desmatamento das margens ciliares, expansão do capitalismo na atividade pesqueira, dentre outras (DUARTE-ALVES e JUSTOS, 2011), esta é uma das principais atividades desenvolvidas pelas comunidades de pescadores e gera renda familiar (LIMA e VELASCO, 2012),

Para Diegues (1995), na pesca artesanal durante sua vida os pescadores acumulam conhecimento sobre a biologia e ecologia dos peixes, o ambiente explorado, identificação do local de pesca,condições de marés, uso e manejo dos apetrechos de pesca. Para Marques (1995), alguns grupos de pescadores possuem conhecimento sobre peixes similar ao ictiológico acadêmico que contribui para o aperfeiçoamento da pesca.

A atividade pesqueira é uma das atividades que consiste em um dos principais desafios ao processo de desenvolvimento regional pela necessidade de manter a conservação do meio ambiente e o uso sustentável dos recursos naturais. Apresenta-se como novo modelo para o desenvolvimento que agrega os aspectos sociais, ecológicos e econômicos (FIDALGA et al., 2014). A aquicultura, no Piauí, produz anualmente 10.400 toneladas de pescado, de acordo com dados coletados pelo IBGE em 2017, onde são geradas 7.700 toneladas de peixes e 2.700 toneladas de camarão. A produção anual atinge 87,5 milhões com meta de produção de 16.000 toneladas para 2023 (SEAP, 2018).

No Brasil, trabalhos realizados com pescadores artesanais têm contribuído com o conhecimento socioeconômico e socioecológico (RAMIRES et al., 2012b), podendo ser citados: Begossi e Garavello (1990) que aborda os aspectos etnoictiológicos detalhando as espécies de peixes usadas para consumo, venda e/ou fins medicinais na comunidade de pescadores no Médio Tocantins, entre as cidade de Imperatriz (Maranhão) e Estreito (Tocantins); Lopes e Souza (2015) que investigaram dentre outros aspectos os apetrechos mais utilizados e os peixes mais capturados pela comunidade de Sacaí, município de Caracaraí, estado de Roraima; Meireles et al. (2017) que descreveram sobre as técnicas de pesca e o conhecimento sobre a atividade pesqueira na comunidade Passarinho, Ilha das Canárias, Maranhão, nordeste Brasileiro e Santos (2017) que estudou o conhecimento etnozoológico e etnoecológico dos pescadores artesanais da comunidade de Miguel Alves, estado do Piauí.

Dentre os autores que realizaram trabalhos com pescadores artesanais no estado do Piaú, destacam-se Amorim (2010) que estudou sobre os modos e artes da pesca e a construção de embarcações com pescadores artesanais do bairro Poti Velho, Teresina; Nascimento (2014) que realizou um estudo em comunidades pesqueiras nos municípios de Cajueiro da Praia e Parnaíba, relatando sobre meios e estratégias de conservação das espécies utilizadas e o incentivo ao resgate do conhecimento popular; Santos et al. (2015) realizaram estudo na comunidade de pescadores Z18, município de União, abordando sobre a arte e estratégias de pesca e reparo de canoas e Santos et al. (2018) que caracterizou a atividade pesqueira na comunidade de pescadores artesanais de Miguel Alves, abordando os apetrechos de pesca utilizados e a identificação do conhecimento etnoictiológico.

Sobre trabalhos de ictiofauna para o estado do Piauí, citam-se os de trabalhos de Melo et al. (2016) investigaram a ictiofauna do baixo curso do rio Parnaíba, nordeste do Brasil, este estudo 
Amorin et al. Entre a terra e a água: a pesca e o conhecimento etnoictiológico dos pescadores artesanais. Ethnoscientia 4, 2019. DOI: 10.22276/ethnoscientia.v4i1.240

apresentou grande similaridade da ictiofauna entre o baixo rio Parnaíba e a Bacia Amazônica; Soares (2016) realizou o estudo na bacia do rio Parnaíba, Piauí, o reservatório de Boa Esperança apresentou uma ictiofauna com baixa similaridade e predominância de espécies migratórias; Ramos et al. (2017) estudaram as espécies de Hypostomuseptingi (Siluriformes: Loricariidae) existente na bacia do rio Parnaíba, Piauí e a bacia do rio São Francisco, Bahia, no qual resultaram em espécies coletadas apenas na bacia do rio Parnaíba e Silva (2018) estudaram sobre a influência de um conjunto-chave de fatores socioeconômicos, manejo da pesca sobre o conhecimento da riqueza e da composição de espécies de peixes no município de Amarante, Piauí, Brasil.

A pesca é importante na dinamização da economia local e proporciona conhecimento sobre conservação e manejo dos recursos. Desta forma, este estudo trata do conhecimento que os pescadores artesanais possuem sobre a ictiofauna e visa contribuir para o conhecimento da diversidade de peixes, usos, modos de coleta, instrumentos e estratégias utilizadas, a partir da percepção dos pescadores artesanais do rio Poti, município de Castelo do Piauí, estado do Piauí, nordeste do Brasil.

\section{METODOLOGIA}

Área de estudo

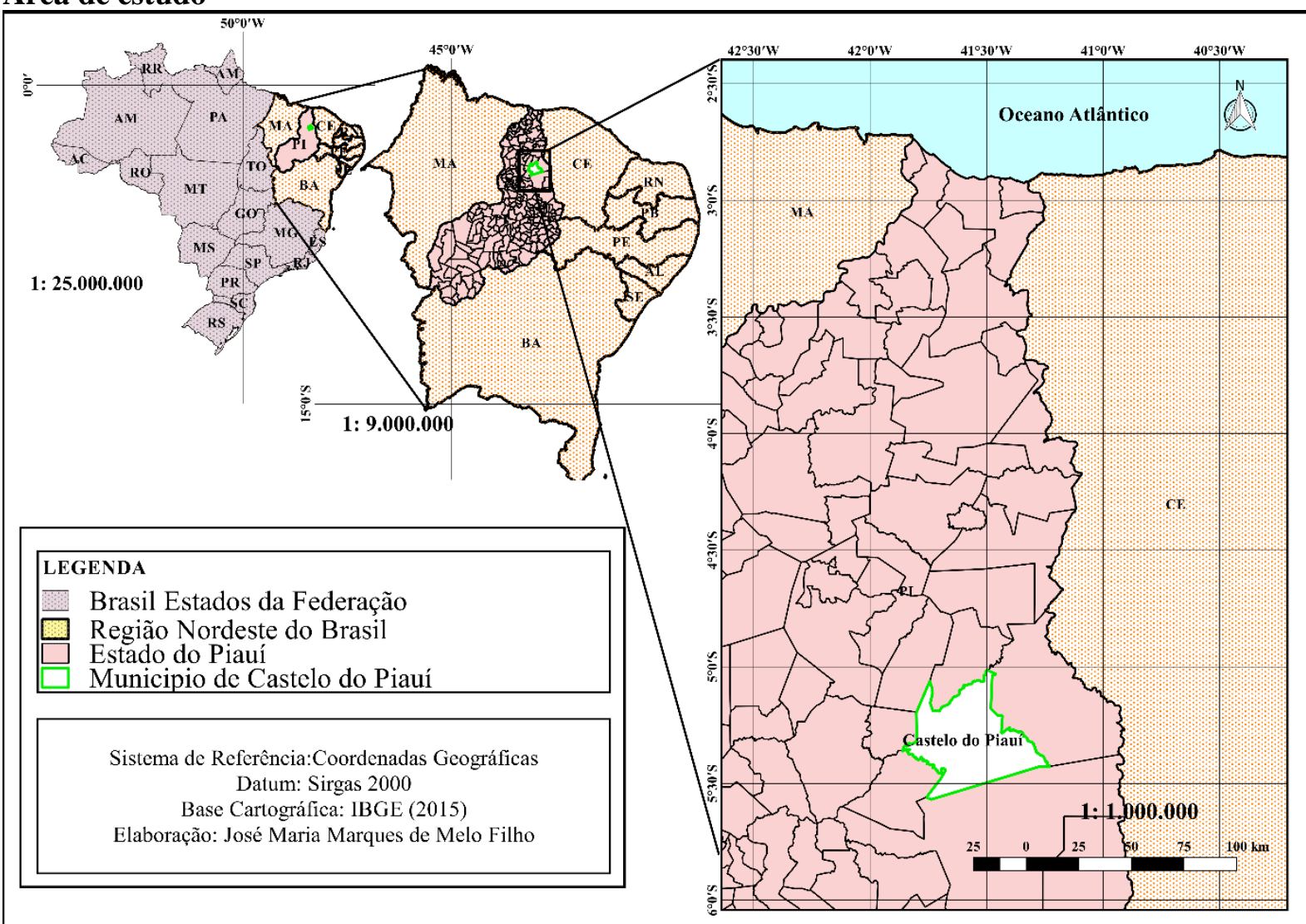

Figura 1. Localização do município de Castelo do Piauí, Piauí, Brasil. Fonte: IBGE (2015). Elaborado por José Maria Marques de Melo Filho (2019).

O município de Castelo do Piauí possui uma área de $2.381,083 \mathrm{~km}^{2}$, situado a 239 m de altitude (coordenadas 5 $5^{\circ} 19^{\prime} 20^{\prime \prime} \mathrm{S}$ e $41^{\circ} 33^{\prime} 09^{\prime}$ 'W na sede municipal), com população estimada de 19.410 mil habitantes (Figura 1). A densidade demográfica é de 9,01 habitantes $/ \mathrm{km}^{2}$, onde 6.859 habitantes vivem na zona rural. Seu nome Castelo vem de uma pedra em forma de castelo, que fica as margens do rio Poti e da Rodovia PI-115. A distância do município para a capital é de $190 \mathrm{~km}$ pela PI-115 e BR 316 (IBGE, 2016).

O município de Castelo do Piauí é drenado pelos rios Poti Cais, riachos Sambaíba, São Francisco e São Miguel (AGUIAR e GOMES, 2004). O rio Poti, principal rio do município, formado pela junção dos riachos Santa Maria e Algodões, nasce na Serra da Joaninha no estado do Ceará e desagua no rio Parnaíba (DAMASCENO et al., 2008). Possui uma área de $538 \mathrm{~km}$ da nascente à foz (IBGE, 2016), com disponibilidade hídrica superficial na micro bacia do rio Poti de aproximadamente 3,8 bilhões de $\mathrm{m}^{3}$, com extensão total de $52.370 \mathrm{~km}^{2}$ (DAMASCENO et al., 2010). 
Amorin et al. Entre a terra e a água: a pesca e o conhecimento etnoictiológico dos pescadores artesanais. Ethnoscientia 4, 2019. DOI: 10.22276/ethnoscientia.v4i1.240

As temperaturas mínimas registradas são de $23^{\circ} \mathrm{C}$ e máxima de $35^{\circ} \mathrm{C}$, com clima quente tropical, alternado de úmido a seco, período seco de seis meses (meados de junho a meados de dezembro) (CEPRO, 2013). A precipitação pluviométrica fica em torno de 1.042,3 $\mathrm{mm}$. O solo é podzólico vermelho-amarelo distrófico e associado a solos concessionários tropicais e areias quartzosas distróficas, constituído de uma vegetação de campo cerrado, com manchas de cerradão e caatinga arbórea e arbustiva (CEPRO, 2013).

\section{Coleta de dados etnoictiológicos}

O projeto foi submetido ao Comitê de Ética e Pesquisa da Universidade Federal do Piauí UFPI, sobre número do parecer: 2.049.486 (CAAE: 65343517.5.0000.5214). A licença para a coleta do material biológico foi concedida pelo Sisbio (Sistema de Autorização e Informação em Biodiversidade) com número 56250-1 e cadastro no SISGEN (Patrimônio Genético e do Conhecimento Tradicional Associado) $\mathrm{n}^{\circ}$ AEF5EB2.Os entrevistados foram esclarecidos sobre o propósito do estudo antes da realização da pesquisa com a apresentação do termo de consentimento livre e esclarecido-TCLE e após foram solicitadas suas assinaturas. No caso dos informantes que não assinaram, foi solicitada a impressão de suas digitais no TCLE. Após este procedimento foi entregue uma cópia do termo para os voluntários no estudo. A técnica utilizada para obter a confiança dos voluntários/participantes foi a de "rapport" (ALBULQUERQUE et al., 2004, BARBOSA, 2007).

O estudo foi realizado com os pescadores associados à colônia de pescadores Z-9, residentes no município de Castelo do Piauí, estado do Piauí, no Nordeste do Brasil durante o período de outubro de 2016 a dezembro de 2017 em 20 expedições.

A pesquisa foi baseada em métodos qualitativos e quantitativos (ALBUQUERQUE et al., 2010). A forma de amostragem foi não probabilística do tipo censo (SILVA et al., 2014). A coleta de dados realizou-se com os pescadores cadastrados na Colônia de Pescadores Z-9, moradores da cidade de Castelo do Piauí, com um total de 29 pescadores cadastrados na Colônia de Pescadores. Foram entrevistados, além dos pescadores, o conjugue e um filho maior de 18 anos, perfazendo o universo amostral de 55 entrevistas, para obtenção dos dados sobre como o conhecimento é repassado para os mais jovens. Foi utilizado o método de entrevistas por residência adotada por Begossi et al. (2009).

As entrevistas foram realizadas com o auxílio de formulários semiestruturados (APOLINÁRIO, 2006) para obtenção de informações sobre a diversidade de peixes utilizada, usos, modos de coleta, instrumentos específicos e estratégias de pesca (ALBUQUERQUE et al., 2004). Os questionários foram aplicados individualmente para evitar interferências, permitir a livre expressão de opinião usando como instrumentos o gravador e diário de campo (SILVA, 2000). Os dados foram transcritos e organizados em planilhas no programa Excel 2010.

Os dados registrados para cada espécie foram: nome popular, nome científico, métodos de captura, importâncias socioeconômica e ambiental. Para a coleta e conhecimento dos espécimes citados foram realizadas turnês-guiadas (BERNARD, 1988), acompanhando as saídas de pesca com os pescadores. O formulário conteve perguntas relacionadas às espécies de peixes capturadas, categoria de uso, local de coleta, parte utilizada, modo de uso e informações sobre a comercialização.

Os peixes citados pelos entrevistados foram capturados com instrumentos seletivos, tais como rede de emalhe, tarrafa, engancho, groseira, anzol de linha e anzol de vara. Posteriormente, foram fixados com formol a 10\%, etiquetados e armazenados em álcool 70\% (SOUZA e AURICCHIO, 2002). As amostras foram processadas, analisadas e incorporadas no Laboratório de Zoologia Antônio João Dumbra da Universidade Federal do Piauí (LZUFPI). A identificação foi realizada com base em Ramos et al. (2014). A nomenclatura científica seguiu o sítio http://www.fishbase.org/search.php, as informações sobre a origem e classificação das espécies seguiram Ramos et al. (2014) e Agostinho et al. (2007).

Os dados, tabelas e gráficos foram organizados no programa Excel 2010. A tabela de diversidade de peixes contém informações sobre o nome da família, nome científico e vulgar, origem das espécies (endêmicas, migratórias e exóticas), espécies tidas como "reimosas" (uso restrito pelo homem), categoria de utilização (alimentícia, medicinal, comercial), valor de uso (geral, atual e potencial), frequência absoluta, frequência relativa, importância relativa e fator de consenso dos informantes.

Os apetrechos de pesca foram identificados através da entrevista com formulários semiestruturados. As espécies registradas no estudo tiveram o valor de uso calculado pela fórmula proposta por Phillips e Gentry (1993 a, b) modificado por Rossato et al. (1999), VU= $\sum U / n$, onde: (VU) 
Amorin et al. Entre a terra e a água: a pesca e o conhecimento etnoictiológico dos pescadores artesanais. Ethnoscientia 4, 2019. DOI: 10.22276/ethnoscientia.v4i1.240

é o índice de Valor de Uso, $\left(\sum \mathrm{U}\right) \mathrm{n}^{\circ}$ de usos mencionados por informante e (n) $\mathrm{n}^{\circ}$ total de informantes. Foi adotada a distinção entre citações de uso geral, atual e potencial no cálculo de VU, de acordo com a proposta de Lucena et al. (2012). O VU atual considera os usos que os informantes efetivamente utilizam em seu cotidiano, e o VU potencial considera os usos que são apenas conhecidos e pouco ou raramente utilizados. VU geral utiliza todas as citações, não difere atual e potencial.

Para as espécies citadas como medicinais foi utilizado o índice de Importância Relativa (IR) (BENETT e PRANCE, 2000). Este índice é dividido em dois fatores, sendo dois (2) o valor máximo que uma espécie pode obter, seguindo a fórmula: IR = NSC + NP; onde: IR = Importância Relativa; $\mathrm{NSC}=$ Número de sistemas corporais; $\mathrm{NP}=$ Número de propriedades. NSC é avaliado pela fórmula: $\mathrm{NSC}=\mathrm{NSCE} / \mathrm{NSCEV}$; onde: $\mathrm{NSCE}=$ número de sistemas corporais tratados pela espécie; NSCEV = número total de sistemas corporais tratados pela espécie mais versátil. $\mathrm{E}$ NP $=\mathrm{NPE} / \mathrm{NPEV}$, onde: NPE $=$ número de propriedades atribuídas para uma espécie, $\mathrm{NPEV}=$ número total de propriedades atribuídas à espécie mais versátil.

A lista de doenças e problemas de saúde tratados está de acordo com a Classificação Estatística Internacional de Doenças e Problemas Relacionados à Saúde - CID-10, que fornece códigos relativos à classificação de doenças e de uma grande variedade de sinais, sintomas, aspectos anormais, queixas, circunstâncias sociais e causas externas para ferimentos ou doenças.

O Fator de Consenso do Informante (FCI) proposto por Trotter e Logan (1986), foi utilizado para análise do uso dos peixes pelos pescadores para identificar as categorias de doenças que possuem maior importância relativa local, apresentado pela fórmula FCI = (nur-nt) / (nur-1), onde: nur = número de citações de usos em cada subcategoria e nt = número de espécies usadas nesta subcategoria.

O grau de conhecimento popular sobre a diversidade de peixes foi calculado por meio da frequência absoluta $(\mathrm{Fa})$ e relativa $(\mathrm{Fr})$ das espécies citadas, observando as famílias e as espécies predominantes e pelo índice de diversidade de Shannon-Wiener (MAGURRAN, 1989; BEGOSSI, 1996). Foi utilizado o método de Rarefação devido os tamanhos amostrais serem distintos. O método calcula o número esperado de espécies em cada amostra para um tamanho de amostra padrão (GOTELLI e COLWELL, 2001). Por apresentarem tamanhos diferentes em relação à faixa etária dos informantes, as amostras foram padronizadas.

\section{RESULTADOS}

Foram identificadas 49 espécies de peixes, distribuídas em 33 gêneros e 20 famílias (Tabela 1). A ordem Characiformes foi a mais representativa com 11 famílias e 19 espécies, seguida da ordem Siluriformes (quatro famílias e 18 espécies) e Perciformes (duas famílias e quatro espécies). As demais ordens Cypriformes, Gymnotiformes, Myliobatiformes e Osteoglossiformes apresentaram uma espécie cada.

A família mais representativa foi Loricariidae com seis representantes, seguido da Serrasalmidae, Auchenipteridae e Pimelodidae com cinco espécies cada. A família Cichlidae apresentou três espécies. Quanto ao valor de uso, Prochilodus lacustris (crumatá) apresentou o maior valor geral e potencial $(\mathrm{VU}$ geral $=2,02 \mathrm{e} \mathrm{VU}$ atual $=1,85 \mathrm{VU}$ potencial $=0,16)$, seguida pelas espécies Leporinus friderici (Piau-de-coco) e Schizodon dissimilis (piau-de-vara), ambas com VU geral $=1,78$, VU atual= 1,75 e VU potencial = 0,04. Tais espécies são utilizadas para alimentação e comercialização (Tabela 1). A espécie citada como mais comum pelos entrevistados foi crumatá (Prochilodus lacustris) $(24,8 \%)$, seguida de branquinha (Curimata macrops) $(23,9 \%)$, cari (Hypostomus plecostomus) $(10,1 \%)$, piranha (Serrasalmus rhombeus) (9,0\%), piranha (Pygocentrus nattereri) (7,3\%), traíra (Hoplias aff. malabaricus) $(7,3 \%)$ e as demais com menos de $5 \%$. Quanto às espécies raras na região citam-se mandubé (Ageneiosus brevifilis) (69,7\%), tambaqui (Colossoma macropomum) (12,1\%), tucunaré (Cichla monoculus) $(9,1 \%)$, bico de pato (Sorubim lima) $(6,1 \%)$ e piranha preta (Pygocentrus piraya) $(3,0 \%)$. Os peixes citados de difícil coleta foram a carpa (Cyprinus spp.) e o tambaqui, ambos com50,0\% de citações. Quanto à origem, a maioria das espécies são migratórias (15), seguidas de endêmicas (sete) e exóticas (cinco) (Apêndice 1).

Quando calculado o FCI para as categorias de uso comercial, alimentícia e medicinal dos peixes, os resultados foram respectivamente, $\mathrm{FCI}_{\mathrm{c}}=0,74, \mathrm{FCI}_{\mathrm{a}}=0,92$ e $\mathrm{FCI}_{\mathrm{m}}=0,93$. O Fator de Consenso dos Informantes (FCI) para as espécies citadas evidenciou 15 espécies de peixes utilizadas na cura de doenças. As que tiveram maior FCI estão na categoria de lesões, envenenamentos e algumas outras consequências de causas externas $(\mathrm{FCI}=1)$, seguidos de enfermidades para doença do aparelho 
Amorin et al. Entre a terra e a água: a pesca e o conhecimento etnoictiológico dos pescadores artesanais. Ethnoscientia 4, 2019. DOI: 10.22276/ethnoscientia.v4i1.240

respiratório $(\mathrm{FCI}=0,93)$ e doenças do sistema esquelético $(\mathrm{FCI}=0,50)$. Assim, observa-se que as espécies que se aproximaram de 1 apresentaram consenso entre os informantes (Tabela 1).

Tabela 1. Consenso entre os pescadores do município de Castelo do Piauí, Piauí, Brasil, para uso dos peixes como medicinais. Para cada sistema foi adicionado um consenso entre os informantes. Legenda: FCI = Fator de Consenso dos Informantes.

\begin{tabular}{|c|c|c|c|c|}
\hline Categorias & $\begin{array}{l}\text { Doenças e problemas } \\
\text { citados }\end{array}$ & Espécies usadas & $\begin{array}{l}N^{0} \text { de } \\
\text { citações }\end{array}$ & FCI \\
\hline $\begin{array}{l}\text { (S00-T98) Lesões, } \\
\text { envenenamentos e algumas } \\
\text { outras consequências de causas } \\
\text { externas }\end{array}$ & $\begin{array}{l}\text { Estrepe, ferimentos com } \\
\text { farpa ou espinho, } \\
\text { machucados }\end{array}$ & Crumatá & 2 & 1,00 \\
\hline $\begin{array}{l}\text { (J00-J99) Doenças do aparelho } \\
\text { respiratório }\end{array}$ & $\begin{array}{l}\text { Gripe, asma, Inflamação } \\
\text { de garganta, dor de } \\
\text { garganta }\end{array}$ & Arraia, sucruiú, traíra & 28 & 0,93 \\
\hline $\begin{array}{l}\text { (R50-R69) Sintomas e sinais } \\
\text { gerais }\end{array}$ & $\begin{array}{l}\text { Dor de ouvido, } \\
\text { alcoolismo, insônia, } \\
\text { falta de memória }\end{array}$ & $\begin{array}{l}\text { Traíra, Arraia, Crumatá, coró, } \\
\text { Piau, Tambaqui, Surubim, } \\
\text { Tucunaré, Curvina, Cari, } \\
\text { Branquinha, Frecheira, Tilápia e } \\
\text { Piranha. }\end{array}$ & 30 & 0,55 \\
\hline $\begin{array}{l}\text { (M00-M99) Doença do sistema } \\
\text { esquelético }\end{array}$ & $\begin{array}{l}\text { Osteoporose, } \\
\text { reumatismo, artrose, dor } \\
\text { no joelho }\end{array}$ & $\begin{array}{l}\text { Traíra, Piranha Preta, Tucunaré, } \\
\text { Arraia, Surubim }\end{array}$ & 9 & 0,50 \\
\hline $\begin{array}{l}\text { (N00-N99) Doença do } \\
\text { aparelho geniturinário }\end{array}$ & $\begin{array}{l}\text { Inflamação de urina, } \\
\text { Inflamação do útero, } \\
\text { inflamação na próstata }\end{array}$ & $\begin{array}{l}\text { Curvina, tambaqui, Crumatá, } \\
\text { Arraia e Piau }\end{array}$ & 8 & 0,43 \\
\hline $\begin{array}{l}\text { (G00-G99) Doenças do sistema } \\
\text { nervoso }\end{array}$ & Epilepsia & Arraia & 1 & 0,00 \\
\hline
\end{tabular}

Quanto ao Índice de Importância Relativa (IR) das espécies, foram relatadas 17 espécies de peixe com uso medicinal, a exemplo, Potamotrygon signata (arraia) foi a espécie mais versátil (IR = 2,00), seguida de Hoplias aff. malabaricus (IR = 1,82) e Prochilodus lacustris (IR = 1,39) (Tabela 1). Quanto ao uso de instrumentos de pesca o mais citado pelos informantes foi o engancho $(94,5 \%)$, seguido de anzol de vara $(72,7 \%)$ e tarrafa $(67,3 \%)$ (Tabela 2$)$.

Tabela 2. Apetrechos de pesca utilizados na comunidade de pescadores artesanais do município de Castelo do Piauí, Piauí, Brasil.

\begin{tabular}{lcc}
\hline Apetrechos de pesca & Quantidades de citações & Porcentagem \\
\hline Engancho & 54 & $94,5 \%$ \\
Anzol de vara & 40 & $72,7 \%$ \\
Tarrafa & 37 & $67,3 \%$ \\
Groseira & 14 & $23,6 \%$ \\
Anzol de linha & 3 & $7,3 \%$ \\
Rede de emalhe & 1 & $1,8 \%$ \\
\hline
\end{tabular}

Fonte: Pesquisa direta (2016-2017).

O engancho é uma rede de espera (também chamada rede de emalhe), confeccionado com linha de nylon, chumbo e isopor, com flutuadores numa extremidade e pesos no lado oposto que possui formato retangular. É armada de um dia para o outro e colocada de um lado a outro do rio de forma vertical. Para o seu manuseio são necessários dois pescadores, um para remar a canoa (conduzir a canoa) e outro para estender a rede ao longo do rio (no fundo, meia água ou na superfície). Vários enganchos são colocados próximos um do outro, com o comprimento e a malha variando de acordo com a espécie que se quer capturar. O uso do engancho, para a maioria dos entrevistados, é devido a possibilidade de maior quantidade de peixes a serem capturados e fácil manejo, a exemplo, Hypostomus plecostomus, Pseudoplatystoma fasciatum, sorubim lima, dentre outros.

A tarrafa, por sua vez, é uma rede em formato de cone, confeccionada com linha de nylon e chumbo que usa peso em toda a sua circunferência, exigindo força e equilíbrio do pescador. É jogada de dentro da canoa, espalhada e depois puxada para dentro da mesma. É utilizado principalmente na captura de espécies grandes, como a Cichlamonoculus, Tilapiarendalli(tilapia), Myleusasterias, e outras. 
A vara de pesca é um instrumento de espera, composta por linha e anzol com isca. Existem dois tipos de anzóis: o de linha - confeccionado com linha de nylon, uma base para enrolar a linha e um peso (chumbada) que ajuda a manter o anzol no fundo da água. Normalmente é usado um pedaço de madeira como base, ou até mesmo uma garrafa pet e o de vara - confeccionado com linha de nylon, chumbo e vara de espécies vegetais resistentes, como o bambu (Bambusa spp). O anzol de vara, por sua vez, é. São usados para a captura de espécies de pequeno porte como o piau-de-vara (Schizodon dissimilis) e o piau-de-coco (Leporinus friderici).

A groseira é confeccionada com várias linhas com ganchos nas pontas, dispostos sobre uma linha central e uma base de madeira para enrolar os anzóis. Estes estão distribuídos em toda a sua extensão, de uma ponta a outra e podem ser de variados tamanhos. São dispostos ao longo do rio até que alguma espécie seja capturada. É um instrumento usado na captura de peixes grandes, tais como o Pseudoplatystoma fasciatum(surubim), sorubim lima (bico-de-pato), Hoplias aff. malabaricus (traíra).

A obtenção do instrumento de pesca é realizada por meio de compra ou produção. A maioria $(69,0 \%)$ dos entrevistados relataram que compram, 21,0\% compram e também produzem, e 10,0\% produzem seu próprio instrumento, que quando necessário fazem reparos.

Os materiais utilizados na fabricação dos instrumentos de pesca, tais como: linha de nylon, agulha, cordão de engancho, boia, chumbada e tabuleta (confeccionado com madeira) são adquiridos nos comércios do próprio município. A linha de nylon e a agulha são os materiais mais utilizados pelos pescadores, pois é com estes que são confeccionados o engancho e a tarrafa. A média do produto pescado é de 24,6 kg/pescaria e o peso pode variar de acordo com a assiduidade do pescador e sua habilidade.

Para os entrevistados, os meses do ano de maior produção de peixes estão no período de novembro a março, com $14,0 \%$ das citações. Observou-se que não há consenso de quando começa e termina o período da piracema. A maioria $(79,0 \%)$ relatou que começa em 15 de novembro e termina em 15 de março, 14,0\% relataram que começa em novembro e termina em março sem citar dias específicos, 4,0\% relataram que começa em 16 de novembro e termina em 16 de março e 3,0\% relataram que começa em 17 de novembro e termina em 15 de março. Observa-se pelos resultados, que embora os pescadores tenham assistência financeira do governo de um salário mínimo durante o período da piracema, estabelecido entre 15 de novembro a 15 de março, época em que é proibida a pesca predatória, alguns pescadores não segue o período estipulado e continuam pescando. Fato este, que pode ser explicado pelo motivo dos pescadores não receberem o benéfico no tempo indicado, ou seja, no prazo estipulado pelo governo. Vindo a receber em atraso, o que prejudica a renda da família que vive basicamente da pesca.

A lua exerce influência na atividade pesqueira, a maioria dos entrevistados $(45 \%)$ relataram que a fase de lua nova é a melhor para a pesca, 39\% consideram que a lua cheia dificulta esta atividade, $7 \%$ que as fases da lua não atrapalham na pesca, $6,0 \%$ que a lua cheia ajuda na captura de alguns peixes e 3,0\% que a lua nova é prejudicial. Já quanto ao período de chuva, a maioria dos entrevistados (67\%) considera desfavorável a atividade de pesca.

Para a diversidade de espécies citadas foram registradas 49 espécies em 164 citações, com valor $H^{\prime}=(3,2089)$. Já com relação à diversidade de citações por gênero foi observado valores próximos para homens e mulheres, onde os homens citaram 29 espécies num total de 84 citações $\left(H^{\prime}=2.313\right)$ e as mulheres 28 espécies em um total de 80 citações $\left(H^{\prime}=2,206\right)$.

Quando comparado a diversidade de espécies por faixa etária, foi observado que os adultos se destacaram com maior índice de diversidade, com 51 espécies de um total de 114 citações $\left(H^{\prime}=2.343\right)$, os idosos apresentaram 22 espécies em um total de 32 citações $\left(\mathrm{H}^{\prime}=2.253\right)$ e os jovens citaram 18 espécies e um total de 18 citações $\left(\mathrm{H}^{\prime}=1.946\right)$. Quando calculada a riqueza de espécies citadas, foi observada a estabilização da curva, mostrando que o esforço amostral foi atingido. O Jackniffer 2 apresentou $(\mathrm{S}=53,50)$ e o Chao $2(\mathrm{~S}=49,82)$ (Figura 2$)$. 
Amorin et al. Entre a terra e a água: a pesca e o conhecimento etnoictiológico dos pescadores artesanais. Ethnoscientia 4, 2019. DOI: 10.22276/ethnoscientia.v4i1.240

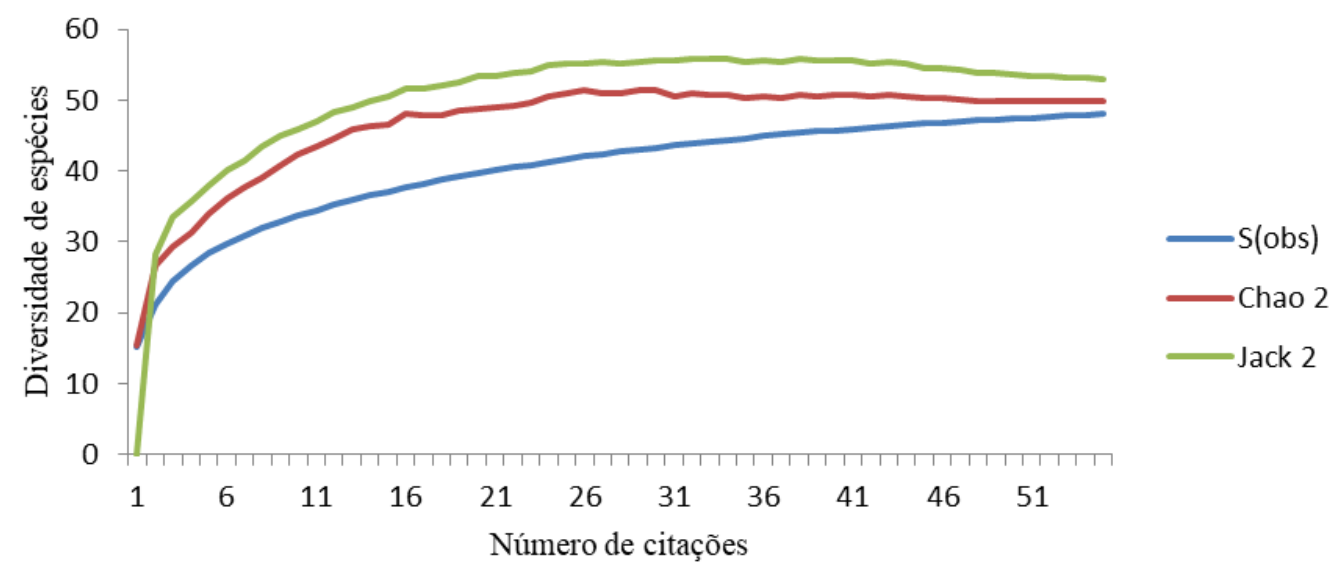

Figura 2. Curva de acumulação representando a riqueza de espécies para o município de Castelo do Piauí, utilizando os estimadores de riqueza Jackniffer 2 e Chao 2.

\section{DISCUSSÃO}

A diversidade de peixes citadas para o município de Castelo do Piauí foi de 49 espécies. Valor superior quando comparado com os registrados nos trabalhos de Piorski et al. (2003), Araújo (2013) e Santos et al. (2015) com um total de 36, 29 e 25 espécies registradas, respectivamente. As populações de peixes de um rio refletem os fatores bióticos e abióticos que ocorrem em determinado momento, além de fatores que são fundamentais para que ocorra o estabelecimento das espécies, tais como: disponibilidade de locais de alimentação, refúgio e reprodução (BENNEMANN et al., 2000; GALVES et al., 2009). Ressalta-se ainda que a construção de barragens, destruição da vegetação ripária e introdução de espécies de outras bacias modificam a fauna (BÖHLKE et al., 1978; CASTRO, 1999).

Pela representatividade de espécies obtidas neste estudo e pelas características locais observadas, tais como: ausência de poluição severa, assoreamento e desmatamento da margem ciliar, distância da zona urbana $(53 \mathrm{~km})$ e mercado extensivo, dentre outras pressões, constata-se que a área estudada não está sofrendo influências antrópicas severas. Vale ressaltar ainda, que na área de estudo são encontradas espécies de peixe de grande porte, como o surubim.

A ordem Characiformes foi a mais representativa com 19 espécies, distribuídas em 11 famílias. Estão incluídas na ordem de maior riqueza de espécies e inclui 2.200 espécies, distribuídas em 24 famílias (FRICKE et al., 2019). Possuem hábitos predominantemente diurnos e variados hábitos alimentares (BURGER, 2008). Seus representantes possuem o corpo coberto por escamas (exceto a cabeça), presença de nadadeira adiposa (exceção da família Erythrinidae), em sua maioria apresentando dentes bem desenvolvidos e grande diversidade morfológica. Nunes (2012) registrou 12 espécies de Characiformes distribuídas em cinco famílias na bacia do rio Pojuca, Bahia.

A ordem Siluriformes foi a segunda mais representativa com 18 espécies distribuídas em quatro famílias. Esta ordem está distribuída nas regiões tropicais de todo o mundo, com a maioria de seus representantes possuindo hábito bentônico e noturno (FERRARIS, 2007). É um grupo composto por espécies que não possuem escamas, podendo apresentar o corpo nu ou coberto por placas dérmicas, presença de um ou mais pares de barbilhões em volta da boca e presença de um acúleo na região anterior das nadadeiras peitorais e/ou dorsal. São representantes os bagres e os cascudos (BUCKUP et al., 2014). Desta ordem destaca-se a família Pimelodidae, com espécies que variam de tamanho (menor que $10 \mathrm{~cm}$ a $1 \mathrm{~m}$ de comprimento) (VIANA et al., 2006).

Loricariidae, ordem Siluriformes, foi a família mais representativa, com seis espécies. Este táxon possui espécies fáceis de serem reconhecidas, pois possuem o revestimento do seu corpo coberto por placas dérmicas, boca ventral e lábios modificados em forma de disco aderente, barbilhões maxilares e o primeiro raio das nadadeiras peitoral e dorsal endurecido (BUCKUP et al., 2014). É um grupo cosmopolita, ocorrente em todos os ambientes de água doce do mundo, com maiores concentrações nas regiões tropicais e neotropicais (MARIGUELA, 2006). Apresentam hábitos bentônicos e noturnos, no entanto, algumas espécies são ativas durante o dia todo (BRITSKI et al., 2007).

A exemplo desta ordem destaca-se a espécie Trachelyopterus galeatus por ser muito comum à sua captura durante as pescarias no rio Poti. Pertence à família Auchenipteridae, ordem Siluriformes. É conhecida pelos pescadores como "porca" ou "serra-negra", ocorrendo em toda a América do Sul 
Amorin et al. Entre a terra e a água: a pesca e o conhecimento etnoictiológico dos pescadores artesanais. Ethnoscientia 4, 2019. DOI: 10.22276/ethnoscientia.v4i1.240

(FERRARIS, 2007). De acordo com Sousa et al. (2016), esta espécie é muito consumida pela população da microrregião de Bragantina, na área de Unidade de Conservação de Uso Sustentável Reserva Marinha de Tracuateua (RESEX), no Pará. Roriz Lemes et al. (2017) avaliaram a biologia reprodutiva desta espécie e verificaram que a reprodução ocorre durante todo o ano, porém o pico reprodutivo ocorre no período de novembro a fevereiro. Assim como na área de estudo, é considerada uma espécie importante na bacia do rio Jequitinhonha, Minas Gerais (LEMES et al., 2017).

A ordem Perciformes apresentou quatro espécies distribuídas em duas famílias. É a ordem de maior diversidade para as espécies de peixes teleósteos. Estes estão constituídos por cerca de 150 famílias e mais de 9.000 mil espécies (Menezes et al., 2007), com distribuição cosmopolita, em todos os continentes, a maioria sendo marinha e ainda com ocorrência em ambientes estuarinos e de água doce (Santos et al., 2004). São caracterizados por apresentarem escamas na maioria das vezes ctenoides, espinhos nas nadadeiras dorsal, pélvica e anal, e nadadeiras pélvicas localizadas na região torácica (BRITSKI et al., 2007).

Dentre as espécies citadas como as mais comuns para este estudo, podemos destacar: Curimata macrops (branquinha), Hypostomus plecostamus(cari), Tilapia rendalli(tilápia). Amorim (2010) apresentou três espécies como as mais comuns capturadas no rio Poti, em Teresina, Piauí: Curimata macrops (branquinha-do-oião), Psectogaster rhomboide (branquinha-do-oin) e Prochilodus lacustres (curimatá) que também foram registradas em Castelo do Piauí. Ramires et al. (2012b) obtiveram 38 espécies citadas como as mais comuns em Ilhabela, São Paulo. Dentre as 15 espécies citadas por Santos et al. (2015) está o crumatá (Prochilodus lacustris) e abranquinha (Psectrogaster rhomboides).

Cinco espécies foram citadas como raras para a área de estudo. Número pequeno quando comparado ao registrado por Netto et al. (2002), 15 espécies, realizado com pescadores de Santa Cruz, Espirito Santo. Santos et al. (2015) também citaram como espécies mais raras o bico-de-pato (Sorubim lima) e o mandubé (Ageneiosus brevifilis). Foi observado que há espécies inseridas no rio por intermédio de enchentes ou por humanos. As espécies exóticas registradas neste estudo foram Roeboides sazimai (cacunda), Curimata macrops (branquinha-do-oião), Colossoma macropomum (tambaqui), Cichla monoculus (tucunaré) e Tilapia rendalli (tilapia).

Dentre as espécies exóticas, citam-se o tucunaré, a tilápia e o tambaqui, tidos na região como peixes de valor comercial e grande procura. A introdução de espécies exóticas provoca um desequilíbrio na fauna nativa, ocasionando o aparecimento de algumas espécies e o desaparecimento de outras (FEITOSA, 2011). O tambaqui e o tucunaré são espécies alóctones, ameaçando outras espécies pela predação (COSTA NETO et al., 2002). A ocorrência de espécies exóticas, como: o tucunaré (Cichla monoculus), relatada por Santos et al. (2010) no reservatório de Furna, Minas Gerais e da tilápia (Coptodon rendalli) (SOARES, 2016) demonstra que a introdução de peixes nas Américas e Europa vem ameaçando a ictiofauna nativa (TARKAN et al., 2014; FREIRE et al., 2016).

Dentre as espécies de peixes com maior valor de uso destaca-se o piau-de-vara (Schizodon dissimilis) e o surubim como muito apreciado e valorizado comercialmente pelos pescadores da área de estudo. A arraia (Dasyatis guttata) foi a espécie que apresentou maior Valor de Uso (VU $=0,058$ ) no estudo realizado por Nascimento (2014), além de possuir uso ornamental e medicinal. Já o tucunaré (Cichla spp.) foi a espécie citada com maior Valor de uso comercial no trabalho de Lopes e Souza (2015), além desta, o piau-cabeça-gorda (Leporinus spp.; Schizodon spp.) e surubim (Pseudoplatystoma sp.), pois possuem grande aceitação no mercado em Manaus. Na categoria alimentícia, tem destaque para o tucunaré (Cichla ssp.), piau-cabeça-gorda (Leporinus spp. Schezodon spp.), além do pacu (Myleus spp.; Metynnis spp.; Milossoma spp.) (LOPES e SOUZA, 2015).

Os peixes também são utilizados para fins medicinais. Costa Neto et al. (2002) citaram o mandi (Prochilodus marggravii), a traíra (Hoplias aff. malabaricus), o cari (Loricariidae), o surubim (Pseudoplatysto macoruscans) e a matrinxã (Brycon reinhardtii). Os autores também observaram na curvina o uso de uma pedra (otólito), encontrada na cabeça, com uso medicinal. Fariña et al. (2011) observaram em comunidades costeiras da Península de Paria, Venezuela, 18 espécies marinhas de peixes, além de uma espécie de réptil nesta categoria. Brandão e Silva (2008) encontraram 11 espécies de peixes com usos medicinais no rio Negro, Manaus, Brasil. Feitosa (2011) relatou o uso de quatro espécies de peixes, tucunaré (Cichla ocellaris), curimatã (Prochilodus brevis), traíra (Hoplias malabaricus) e tilápia (Oreochromis niloticus).

A arraia (Potamotrygon signata), é uma das espécies mais utilizadas para fins medicinais pelos pescadores de Castelo do Piauí. Lopes e Souza (2015) citaram a banha do pirarara 
Amorin et al. Entre a terra e a água: a pesca e o conhecimento etnoictiológico dos pescadores artesanais. Ethnoscientia 4, 2019. DOI: 10.22276/ethnoscientia.v4i1.240

(Phractocephalus sp.) para o uso de enfermidades como a pneumonia. De acordo com Costa Neto e Alves (2010), a banha dos peixes, a exemplo do peixe-elétrico (Electrophorus electricus) é muito utilizada para amenizar pancadas, torções e picadas de insetos, enquanto o baiacu (Sphoeroides testudineus) é utilizado para enfermidades como reumatismo e a traíra (Hoplias malabaricus) no tratamento oftalmológico, como a catarata.

Em se tratando de espécies usadas como alimentícias, existem alguns tabus quanto à ingestão de determinadas espécies, tidas como "reimosas". Esta denominação é devido a sua não recomendação de uso por pessoas que tem algum processo inflamatório, termo este também utilizado por Peirano (1975) e Maués e Maués (1977) para alimentos tidos com ofensivos à saúde humana. A "reima", para os pescadores, se encontra na linha lateral dos peixes e para a sua retirada é necessário que batidas leves sejam realizadas nesta região. A linha lateral, posicionada nos flancos laterais do corpo dos peixes contém poros ou tubos conectados por um longo canal tubular, abrigando órgãos sensoriais (neuromastos) (KARDONG, 2016). A função deste órgão sensorial nos peixes é auxiliar na detecção de vibrações e movimentos ao seu redor dentro da água, detectar as mudanças de pressão e temperatura e responderem às correntes de água (KARDONG, 2016).

Os tabus alimentares estão relacionados às crenças e superstições no consumo de alimentos que são considerados perigosos para a saúde (BATISTA, et al. 2016). Os resultados obtidos neste estudo corroboram com o trabalho de Costa Neto et al. (2002), que identificaram espécies de peixes que são tidos como "reimosas", dentre elas citam-se: curimatá (Prochilodus marggravii), mandi (Pimelodus sp.), piranha-branca (Serrasalmus piraya) e surubim (Pseudoplatystoma coruscans). Para os pecadores entrevistados por estes autores, a presença de couro nas espécies é um dos fatores que determina a reima, proibido para mulheres no período de pós-parto, lactação e menstrual, pessoas no pós-operatório e pessoas com lesões ou infecções pelo corpo. Begossi et al. (2004), em estudo realizado com pescadores da Mata Atlântica e da floresta Amazônica, registraram como "reimosos", o surubim (Pseudoplatystoma fasciatum) e o pacu (Mylossoma, Myleus, Metynnis). Além destes autores, Begossi e Braga (1992), Begossi (1992), Madi e Begossi (1997), Costa et al. (2013), Ramires et al. (2012c) e Batista et al. (2016) também relataram sobre espécies de peixes com tabus alimentares. Os alimentos com restrição estão voltados principalmente para as mulheres em períodos fisiológicos no qual se acredita serem gerados a partir de padrões culturais dentro da sociedade, justificativa esta, dada pelo fato de causar inflamações no local afetado (MARQUES, 2018).

A atividade pesqueira ao longo do rio Poti (município de Castelo do Piauí) é realizada em pontos de pesca, como Poço Amarelo (40 km de distância da cidade), rio Cais (afluente do rio Poti), Cânion do Poti (60 km do município) e Mesa de Pedra (distante $120 \mathrm{~km}$ da cidade), que os pescadores consideram serem mais propícios para a captura e a distância percorrida para o local de pesca pode ser superior a $60 \mathrm{~km}$. Zacarkim et al. (2017) também destacaram as distâncias que os pescadores percorrem em busca da captura do pescado, às vezes, até mais de $250 \mathrm{~km}$ de distância de sua moradia. O Cânion do Poti é o local onde se encontra a maior diversidade destas espécies de peixes, segundo os pescadores.

O período do ano em que ocorre maior quantidade de peixes, segundo registrado neste estudo, é de novembro a março, período em que começam as chuvas na região e maior abundância de alimentos para os peixes. Para Santos et al. (2015) a época mais produtiva na pesca são os meses de maio a julho no município de União, Piauí, Brasil. Enquanto que em Porto Belo, Santa Catarina, Brasil, os meses de maior produção, são de novembro a janeiro, pois nesta época a pesca é proibida, o que contribui para o aumento das espécies (SEDREZ et al., 2013).

Daaddy et al. (2016) relataram que existe diferença em relação aos períodos do ano. O verão (período de seca) é o mais propício para a captura de peixes, pois estes ficam concentrados nos locais com água permanente ou em locais que o nível da água não reduziu totalmente. Os pescadores de Iguape, Cananéia e Peruíbe tem preferência pela época seca (sem chuva) na captura do pescado (RAMIRES et al., 2012a). Ramires et al. (2012a), observaram que há influência de alguns fatores nas pescarias, como chuva, maré e fase da lua. Enquanto Krumme (2004) observou que os peixes no rio Caeté migram acompanhando a maré. Silvano e Begossi (2002) relataram que os pescadores do rio Piracicaba observaram o aumento de peixes migratórios no período chuvoso.

A quantidade de instrumentos de pesca registrados nos estudos realizados é variável, neste estudo foram citados seis tipos. Feitosa (2011) relatou o uso de quatro artefatos de pesca, no qual, o anzol foi registrado como o mais comum. Santos et al. (2015), por sua vez, citaram oito instrumentos de pesca, dentre eles destacou-se o engancho como o mais citado, seguido de vara de pesca, tarrafa, currú, peneira, groseira, garrafa e jiqui. Diferente dos resultados obtidos neste estudo, Baptista (2011) 
Amorin et al. Entre a terra e a água: a pesca e o conhecimento etnoictiológico dos pescadores artesanais. Ethnoscientia 4, 2019. DOI: 10.22276/ethnoscientia.v4i1.240

observou que todos os pescadores do rio Tramandaí, no Rio Grande do Sul, fazem o uso da tarrafa, rede e espinhel. A rede de espera foi a mais citada nos trabalhos de Ramires et al. (2012a) e Zacarkim et al. (2017). Santos et al. (2015), por sua vez, citaram o engancho como um dos instrumentos mais utilizados pelos pescadores de União, Piauí. No caso da tarrafa, os pescadores utilizam embarcação, a remo ou a motor, para chegar até o ponto de captura, onde é lançada sobre as águas, repetidas vezes, para poder apanhar o maior número de espécies possível, corroborando com as observações de Silva-Gonçalves e D’Incão (2016).

A quantidade de pescado capturado por mês para a área estudada foi de $24,6 \mathrm{Kg} /$ pescaria. Este resultado também foi registrado em Furlan et al. (2016). O procedimento de acondicionamento empregado nas pescarias é o mesmo relatado por Amorim (2010), Sedrez et al. (2013) e Meireles et al. (2017), no qual os pescadores utilizam gelo e em alguns casos realizam a salga do produto pescado.

Com relação à diversidade de citações entre gêneros, foi observado que tanto homens como mulheres possuem conhecimentos próximos em relação à pesca. Resultados semelhantes foram observados por Santos et al. (2015), onde homens $\left(H^{\prime}=3,053\right)$ e mulheres $\left(H^{\prime}=3,095\right)$ mostram terem conhecimento bem próximos e Sousa (2010), em estudo realizado no estado do Piauí, na comunidade Barra Grande, onde ambas as comunidades estudadas mostraram valores bem próximos em relação ao conhecimento da pesca. Estes resultados se aproximam pelo fato das mulheres estarem diretamente inseridas na pesca e realizando os mesmos esforços que os homens. Já no estudo de Nascimento (2014), os homens se sobressaíram em relação às mulheres quanto ao conhecimento das espécies, devido ao contato direto do pescador com a natureza. Desta forma, podemos observar que cada região tem uma característica própria quanto ao conhecimento da pesca pelos pescadores artesanais.

Quando comparado o conhecimento por faixa etária, pode-se observar que os adultos apresentaram maior índice de diversidade. Comparando com os trabalhos de Nascimento (2014) e Fonseca-Kruel e Peixoto (2004) a maior experiência dos idosos resulta no maior conhecimento empírico em relação aos demais. Porém, no trabalho de Sousa (2010) os jovens apresentaram maior conhecimento em relação à pesca. Enquanto que Santos et al. (2015), não obtiveram diferenças significativas entre adultos e idosos, porém, os jovens mostraram ter menor conhecimento em relação aos demais. Estes resultados mostram que o conhecimento obtido se deve ao fato dos adultos manterem uma atividade mais intensa e contato maior com o ambiente em que realizam suas atividades, os idosos por sua vez, apresentam maior experiência relacionada à pesca.

\section{CONCLUSÕES}

Os pescadores cadastrados na colônia Z-9, residentes no município de Castelo do Piauí, são detentores de conhecimento empírico em relação à atividade pesqueira e esta é a principal atividade de subsistência desta comunidade. Além disto, os pescadores possuem entendimento quanto ao uso das espécies na cura de algumas enfermidades.

A área estudada apresenta alta diversidade de peixes quando comparada a outras áreas. Entretanto, o Rio Poti é muito extenso, sendo imprescindível a realização de estudos em toda a sua extensão para ter uma estimativa melhor de toda a diversidade que o compõe. Os rios, riachos e suas cabeceiras são ambientes que devem receber prioridade nos estudos, antes que muitas informações sejam perdidas.

Embora haja outros instrumentos de pesca, o engancho é o mais utilizado, pois facilita a captura de uma quantidade maior de pescado, além disso, este apetrecho facilita a vida dos pescadores, pois não necessitam passar a noite acordados em vigília da armadilha. Em relação ao número de citações de espécies, a pesquisa mostrou que não houve diferenças significativas quando comparado o gênero masculino e feminino; e quanto à faixa etária, os jovens demonstraram ter menor conhecimento. Quando comparados adultos e idosos, estes não diferem significativamente entre si e a atividade pesqueira é desenvolvida tanto por homens como por mulheres.

\section{REFERÊNCIAS}

ALBUQUERQUE, U.P.; LUCENA, R.F.P.; CUNHA, L.V.F.C. Métodos e técnicas na pesquisa etnobotânica. Recife: NUPEEA, 2004.

ALBUQUERQUE, U.P.; LUCENA, R.F.P.; CUNHA, L.V.F.C. Métodos e técnicas na pesquisa etnobotânica. Recife: NUPEEA, 2010. 560 p.

AMORIM, A.N. Etnobiologia da comunidade de pescadores artesanais urbanos do bairro Poti Velho, Teresina/PI, Brasil. 2010. 124 f. Dissertação (Mestrado em Desenvolvimento e Meio Ambiente) - Universidade Federal do Piauí, PI. Teresina. 
Amorin et al. Entre a terra e a água: a pesca e o conhecimento etnoictiológico dos pescadores artesanais. Ethnoscientia 4, 2019. DOI: 10.22276/ethnoscientia.v4i1.240

APOLINÁRIO, F. Introdução à análise quantitativa de dados. In: Metodologia científica - Filosofia e prática da pesquisa. São Paulo: Thomson Leaming. 2006. p. 145-168.

ARAÚJO, M.P.Etnobiologia da comunidade pesqueira Passarinho, Ilha das Canárias, Reserva Extrativista Marinha Delta do Parnaíba/PI. 2013. 142 f. Dissertação (Mestrado em Desenvolvimento e Meio Ambiente) Universidade Federal do Piauí, Teresina.

BAPTISTA, C.P.B. O conhecimento ecológico local e a percepção ambiental de uma população de pescadores do Rio Grande do Sul. 2011. 91 f. Tese (Doutorado em Biologia) Universidade do Vale do Rio dos Sinos, São Leopoldo.

BARBOSA, A.R. Os humanos e os répteis da mata: uma abordagem etnoecológica de São José da Mata - Paraíba. 2007. 144 f. Dissertação (Mestrado em desenvolvimento e Meio Ambiente) - Universidade Federal da Paraíba, João Pessoa.

BATISTA, L.P.P.; BOTERO, J.I.S.; PAULA, E.O.; SILVA, E.V. Etnotaxonomia e tabus alimentares dos pescadores artesanais nos açudes Araras e Edson Queiroz, bacia do Rio Acaraú, Ceará, Brasil. RevistaEntornoGeográfico, n. 12, p. 34-49, 2016.

BEGOSSI, A.; GARAVELLO, J.C. Notes on the ethnoicthyology of fishermen from the Tocantins river (Brazil). Acta Amazonica, Manaus, v. 20, p. 341-351, 1990.

BEGOSSI, A. Foods taboos Island (Brazil): Their significance and relation to folk medicine. Journal of Ethnobiology, Tacoma, v. 12, n. 1, p. 117-139, 1992.

BEGOSSI, A.; BRAGA, F.M.S. Food taboos and folk medicineamong fishermen form the Tocantins River (Brazil). Amazoniana, Manaus, v. 12, n. 1, p. 101-118, 1992.

BEGOSSI, A. Fishing activities and strategies at Buzios Island. In: World Fisheries Congress, Atenas. Proceedings of the WFC, fisheries resource and utilization, v. 2. p. 125-141, 1996.

BEGOSSI, A.; HANAZAKI, N.; RAMOS, R.M. Food chain and the reasons for fish food taboos among Amazonian and Atlantic Forest fishers (Brazil). Ecologicalapplications, Washington,v. 14, n. 5, p. 1334-1343, 2004.

BEGOSSI, A. (Org.). Ecologia de pescadores da Matta Atlântica e da Amazônia. São Paulo: Hucitec/Nepam/Unicamp, 2004, 331 p.

BEGOSSI, A.; LOPES, P.F.; OLIVEIRA, L.E.C.; NAKANO, H. Ecologia de pescadores artesanais da Baía de Ilha Grande.Canadá. Rio de Janeiro: IBIO/Ministério da Justiça. 2009.

BENNEMAnN, S.T.; SHIBATTA, O.A.; GARAVELlO, J.C. Peixes da bacia do rio Tibagi: uma abordagem ecológica. Londrina: EDUEL, 2000.

BERNARD, H.R. Research in cultural anthropology. Sage. Newbury Park, CA, EEUU. 1988.

BÖHLKE, J.E.; WEITZMAN, S.H.; MENEZES, N.A. Estado atual da sitemática dos peixes de água doce da América do Sul. Acta Amazonica, Manaus, v. 8, n. 4, p. 657-677, 1978.

BRAGA, M.A.; BRAGA, E.O. Indígenas, camponeses e urbanos na pesca como ela é: os pescadores artesanais de Baía da Traição/PB. Inter Scientia, v. 5, n. 1, p. 7-17, 2017.

BRAGA, H.O.; PARDAL, M.A.; AZEITEIRO, U.M. Sharing fishers' ethnoecological knowledge of the European pilchard (Sardinapilchardus) in the westernmost fishing community in Europe. JournalofEthnobiologyandEthnomedicine,Pollenzo, v. 13, n. 52, p. 1-13, 2017.

BRANDÃO, F.C.; SILVA, L.M.A. Conhecimento ecológico tradicional dos pescadores da floresta nacional do Amapá. Revista UAKARI, São João da Ponta, v. 4, n. 2, p. 55-66, 2008.

BRITSKI, H.A.; SILIMON, K.Z.S.; LOPES, B.S. Peixes do Pantanal: manual de identificação $2^{\mathrm{a}}$ edição revista e ampliada. Brasília, EMBRAPA, 2a Ed., v. 1, 2007.

BUCKUP, P.A.; BRITTO, M.R.; SOUZA-LIMA, R.; PASCOLI, J.C.; VVILLA-VERDE, L.; FERRARO, G.A.; SALGADO, F.L.K.; GOMES, J.R. GUIA de Identificação das Espécies de PEIXES da Bacia do Rio das Pedras Município de Rio Claro, RJ. Rio de Janeiro: The NatureConservancy, 2014.

BUCKUP, P.A.; MENEZES, N.A.; GHAZZI, M.S. Catálogo das espécies de peixes de água doce do Brasil. Rio de Janeiro: Museu Nacional, 2007. 195 p.

BURGER, R. Ictiofauna do Baixo São Francisco à Jusante da Barragem de Xingó: Inventário e Caracterização Taxonômica. Monografia não publicada, Universidade Federal da Bahia, Salvador/BA, 2008.

FUNDAÇÃO CENTRO DE PESQUISA ECONÔMICAS E SOCIAIS DO PIAUÍ - CEPRO. Diagnóstico socioeconômico, Castelo do Piauí: Características morfoclimáticas. 2013. Disponível em http://www.cepro.pi.gov.br/diagsoceco.php. Acesso em: 22 jun. 2017.

COSTA NETO, E.M.; DIAS, C.V.; MELO, M.N.. O conhecimento ictiológico tradicional dos pescadores da cidade de Barra, região do médio São Francisco, Estado da Bahia, Brasil. Revista Acta Scientiarum, Maringá, v. 24, n. 2, p. 561-572, 2002.

COSTA NETO, E.M.; ALVES, R.R.N. Estado da arte da zooterapia popular no Brasil. In: COSTA NETO, E.M; ALVES, R.R.N. Zooterapia: Os animais na medicina popular brasileira. Recife: Nuppea. 2010. 268 p.

COSTA, T.V.; SILVA, R.R.S.; SOUZA, J.L.; BATALHA, O.S.; HOSHIBA, M.M. Aspectos do consumo e do comércio de pesca em Parintins. Boletim do Instituto de Pesca, São Paulo, v. 39, n. 1, p. 63-75, 2013.

DAADDY, M.D.V.; SANTOS, C.; BRANDÃO, R.M.L. Pesca do apaiari, Astronotusocellatus(Agassiz, 1831), e perfil socioeconômico dos pescadores artesanais de uma região da Amazônia brasileira. Boletim do Museu Paraense Emílio Goeldi. Ciências Humana, Belém, v. 11, n. 2, p. 363-378, 2016.

DAMASCENO, L.M.O.; ANDRADE JÚNIOR, A.S.; DIAS, N.S.; FRANCO, J.L.D.; SILVA, Ê.F.F. Qualidade da água do rio Poti para consumo humano, na região de Teresina, PI. Revista Verde de Agroecologia e Desenvolvimento Sustentável, Pombal, v. 3, n. 3, p 116-130, 2008. 
Amorin et al. Entre a terra e a água: a pesca e o conhecimento etnoictiológico dos pescadores artesanais. Ethnoscientia 4, 2019. DOI: 10.22276/ethnoscientia.v4i1.240

DAMASCENO, L.M.O;; ANDRADE JÚNIOR, A.S.; DIAS, N.S.; FRANCO, J.L.D.; SILVA, Ê.F.F. Aspectos qualitativo da água do rio Poti na região de Teresina, PI. Revista Ciências Agronômica, Fortaleza, v. 41, n. 1, p. 139148,2010 .

DIEGUES, A.C.S. Pesca e Marginalização no Litoral Paulista. 1973. 190 f. Dissertação (Mestrado em Ciências Sociais) - Universidade de São Paulo.

DIEGUES, A.C.S. Povos e Mares: Leituras em Sócio- Antropologia Marítima. São Paulo: Núcleo de Apoio à Pesquisa de Populações Humanas em Áreas Úmidas Brasileiras, 1995.

DIEGUES, A.C.S. Environmental impact assessment: The point of view of artisanal fishermen communities in Brazil. Ocean\&Coastal Management, Hull, v. 39, p. 119-133, 1998.

DUARTE ALVES, A.; JUSTO, J.S. Histórias de Pescadores: estudo com ribeirinhos desalojados por uma hidrelétrica. PsicologiaPolítica, São Paulo, v. 22, n. 11, p. 309-328, 2011.

FARIÑA, A.; RUIZ-VELÁSQUEZ.; ROJAS, M.; PEÑUELA, J.; GONZÁLEZ, N. Etnobiología marina y aspectos pesquerosen seis comunidades costeras de la Península de Paria, Venezuela. Interciência, Las Condes, v. 36, n. 4, p. 256-264, 2011.

FEITOSA, M.A. Pesca artesanal no semiárido Paraibano: um enfoque etnoictiológico. 2011. 114 f. Dissertação (Mestrado em Desenvolvimento e Meio Ambiente) - Universidade Federal da Paraíba, João Pessoa.

FERRARIS, C.J. Checklist of catfishes, recent and fossil (Osteichthyes: Siluriformes), and catalogue of siluriformes primary types. Zootaxa, Auckland, v. 1418, p. 1-628, 2007.

FIDALGA, A.B.P.; SEIXAS, S.; AZEITEIRO, U.M. Estudo das percepções da comunidade da Palmeira (Ilha do Sal, Cabo Verde) sobre a Sustentabilidade das Pescas. Revista da Gestão Costeira Integrada/JournalofIntegratedCoastal Zone Management,Coimbra, v.14, n.1, p. 41-49, 2014.

FONSECA-KRUEL, V.S.; PEIXOTO, A.L. Etnobotânica na Reserva Extrativista Marinha de Arraial do Cabo, RJ, Brasil. Acta Botanica Brasílica, Belo Horizonte, v. 18, n. 1, p. 177-190, 2004.

FREIRE, K. M. F. et al. Brazilian recreational fisheries: current status, challenges and future direction. Fisheries Management and Ecology, Hull, v. 23, p. 276-290, 2016.

FRICKE, R.; ESCHMEYER, W.N.; FONG, J.D. Species by family/subfamily. 2019. Disponívelem: http://researcharchive.calacademy.org/research/ichthyology/catalog/SpeciesByFamily.asp. Acesso em: 25 ago. 2019.

FURLAN, V.J.M.; CAMPOS, I.P.; CENTENARO, G.S. Caracterização da atividade pesqueira e aspectos da comercialização do pescado no município de Itaqui-RS, Brasil. Revista Visão em Debate: Sociedade, Ciências e Tecnologia, Itaqui, v. 4, n. 4, p. 43-50, 2016.

FUNDAÇÃO INSTITUTO BRASILEIRO DE GEOGRAFIA E ESTATÍSTICA - IBGE. Censo Populacional. 2010. Disponível

em:

<http://cidades.ibge.gov.br/xtras/temas.php?lang=\&codmun=220260\&idtema=16\&search=piaui|castelo-dopiaui|sintese-das-informacoes> Acesso em: 19 jun. 2016.

FUNDAÇÃO INSTITUTO BRASILEIRO DE GEOGRAFIA E ESTATÍSTICA - IBGE. Síntese das informações. 2016. Disponível

em:

$<$ https://cidades.ibge.gov.br/xtras/temas.php?lang=\&codmun=220260\&idtema=16\&search=||s\%EDntese-dasinforma\%E7\%F5es>. Acesso em: 22 jan. 2018.

GALVES, W.; SHIBATTA, O.A.; JEREP, F.C. Estudos sobre diversidade de peixes da bacia do alto rio Paraná: uma revisão histórica. Semina: Ciências Biológicas e da Saúde, Londrina, v. 30, n. 2, p. 141-154, 2009.

KRUMME, U.Patterns in tidal migration of fish in a Brazilian mangrove channel as revealed by a vertical split-beam echosounder. FisheriesResearch, Vancouver,v. 70, n. 1, p. 1-15, 2004.

LEITE, R.S. O Jacaré Caimancrocodilus(LINNAEUS, 1758) e a comunidade de Ilha Grande, Piauí, APA Delta do Parnaíba, Brasil. Teresina: 2010. 128 f. Dissertação (Mestrado em Desenvolvimento e Meio Ambiente) Universidade Federal do Piauí, Teresina.

LEMES, D.L.R; VIZIOLI, B.; MARCON, L.; BAZZOLI, N. Reproduction of the internal inseminator Trachelyopterusgaleatus (Linnaeus, 1766) (Siluriformes: $\quad$ Auchenipteridae). JournalofAppliedIchthyology, Berlin, v. 33, n. 1, p. 69-74, 2017.

LIMA, B.B., VELASCO, G. Estudo piloto sobre o autoconsumo de pescado entre pescadores artesanais do estuário da lagoa dos Patos, RS, Brasil. Boletim do Instituto de Pesca, São Paulo, v. 38, n. 4, p. 357-367, 2012.

LOPES, P.L.J.; SOUZA, J.M. Valor e categorias de uso dos apetrechos de pesca e das etnoespécies de peixes da comunidade de pescadores artesanais de Sacaí, Caracaraí - R, Brasil. RevistaBrasileira de Agroecologia, Pelotas, v. 10, n. 2, p. 100-109, 2015.

LUCENA, R.F.P.; MEDEIROS, P.M.; ARAÚJO, E.L.; ALVES, A.G.C.; ALBUQUERQUE, U.P. The ecological apparency hypothesis and the importance of useful plants in rural communities from Northeastern Brazil: An assessment based on use value. Jornal of Environmental Management, United States, v. 96, n. 1, p. 106-115. 2012.

MADI, E.; BEGOSSI, A. Pollution and food taboos: s practical reason? Journal of Human Ecology, Haryana, v. 8, n. 6, p. 405-408, 1997.

MAGURRAN, A. Diversidad ecológica y su medición. Barcelona: Ediciones Vedra. 1989. 200 p.

MARIGUELA, T.C. Análise filogenética da subfamília Callichthyinae (Teleostei: Siluriformes: Callichthyidae) com base em sequências de DNA nuclear e mitocondrial. 2006. 64 f. Dissertação de Mestrado não publicada, Universidade Estadual Paulista, São Paulo.

MARQUES, C.R.S. Alimentação, saúde e cultura: um estudo das práticas alimentares em uma comunidade remanescente de quilombo na Amazônia brasileira. 2018. 121 f. Dissertação (Mestrado em Saúde Pública) - Escola Nacional de Saúde Pública Sergio Arouca, Fundação Oswaldo Cruz, Rio de Janeiro. 
Amorin et al. Entre a terra e a água: a pesca e o conhecimento etnoictiológico dos pescadores artesanais. Ethnoscientia 4, 2019. DOI: 10.22276/ethnoscientia.v4i1.240

MARQUES, J.G.W. Etnoictiologia: pescando pescadores nas águas da transdisciplinaridade. Revista Ouricuri, Juazeiro, v. 2, n. 2, p. 9-36, 2012.

MARQUES, J.G.W. Pescando pescadores: Ciência e etnociência em uma perspectiva ecológica. São Paulo: Nupaub/USP. 2001. 258 p.

MARQUES, J.G.W. Pescando pescadores:Etnoecologia abrangente no baixo São Francisco. São Paulo: NUPAUB/USP. 1995. 285 p.

MAUÉS, R.H.; MOTTA-MAUÉS, M.A. O modelo da "reima": representações alimentares em uma comunidade amazônica. Anuário Antropológico,Brasília, v. 77, p. 120-147. 1977.

MEIRELES, M.P.A.; MEIRELES, V.J.S.; VIEIRA, L.S.; BARROS, R.F.M. Características da pesca artesanal realizada na comunidade Passarrinho/Ilha das Canárias/MA. Gaia Scientia, João Pessoa, v. 11, n. 3, p. 12-26, 2017.

MELO, F.A.G.; BUCKUP, P.A.; RAMOS, T.P.A.; SAOUZA, A.K.N.; SILVA, C.M.A.; COSTA, T.C.; TORRES, A.R. Fish fauna ofthelowercourseofthe Parnaíba river,

northeasternBrazil. Boletim do Museu de Biológia Mello Leitão, Santa Teresa, v. 38, n. 4, p. 363 - 400. 2016.

MENEZES, N.A.; WEITZMAN, S.H.; OYAKAWA,O.T.; LIMA, F.C.T.; CORREA E CASTRO, R.M.; WEITZMAN, M.J. Peixes de Água Doce da Mata Atlântica - Lista preliminar das espécies e comentários sobre conservação de peixes de água doce neotropicais. Museu de Zoologia da Universidade de São Paulo, 2007. 408p.

MOURÃO, J.S.; NORDI, N. Etnoictiologia de pescadores artesanais do estuário do Rio Mamanguape, ParaíbaBrasil. Boletim do Instituto de Pesca, São Paulo, v. 29, n. 1, p. 9-17, 2003.

NASCIMENTO, M.G.P.Etnobotânica e Etnozoologia em comunidades pesqueiras de Parnaíba e Cajueiro da Praia, Piauí, Brasil. 2014.144 f.Dissertação (Mestrado em Desenvolvimento e Meio Ambiente), Universidade Federal do Piauí, Teresina.

NETTO, R.F.; NUNES, A.G.A.; ALBINO, J. A pesca realizada na comunidade de pescadores artesanais de Santa Cruz/ ES - Brasil. Boletim do Instituto de Pesca, São Paulo, v. 28, n. 1, p. 93-100, 2002.

NUNES, F.C. Estudo taxonômico das espécies de peixes de água doce da Bacia do rio Pojuca, Bahia, Brasil. 2012. 88 f. Monografia (Bacharel em Ciências Biológicas) - Universidade Federal da Bahia. Salvador.

PEIRANO, M.G.S. Proibições alimentares numa comunidade de pescadores. 1975. 165 f. Dissertação (Mestrado em Antropologia Social), Universidade de Brasília, Brasília,

PHILLIPS, O.; GENTRY, A.H. The useful plants of Tambopata, Peru: I. Statistical hypothesis tests with a new quantitative technique. Economic Botany, New York, v. 47. p. 15-32, 1993a.

PHILLIPS, O.; GENTRY, A. H. The useful plants of Tambopata, Peru: II. Additional hypothesis testing in quantitative ethnobotany. Economic Botany, New York, v. 47, p. 33-43, 1993 b.

PINTO, M.F.; MOURÃO, J.S.; ALVES, R.R.N. Ethnotaxonomical considerations and usage of ichthyofauna in a fishing community in Ceará State, Northeast Brazil. Journal of Ethnobiology and Ethnomedicine, Pollenzo, v.9, n. 17, p. 1-11, 2013.

PINTO, M.F.; MOURÃO, J.S.; ALVES, R.R.N. Use of ichthyofauna by artesanal fishermen at two protected areas along the coast of Northeast Brazil. JournalofEthnobiologyandEthnomedicine, Pollenzo, v. 11, n. 20, p. 1-32, 2015.

PIORSKI, N.M.; CASTRO, A.C.L.; PINHEIRO, C.U.B. A prática da pesca entre grupos indígenas das bacias dos rios Pindaré e Turiaçu, no estado do Maranhão, nordeste do Brasil. Boletim do Laboratório de Hidrobiologia, São Luís, v. 16, p. 67-74, 2003.

RAMIRES, M.; BARRELLA, W.; ESTEVES, A.M. Caracterização da pesca artesanal e o conhecimento pesqueiro local no Vale do Ribeira e Litoral Sul de São Paulo. Revista Ceciliana, Santos,v. 4, n. 1, p. 37-43, 2012 a.

RAMIRES, M.; CLAUZET, M.; ROTUDO, M.M.; BEGOSSI, A. A pesca e os pescadores artesanais de Ilhabela (SP), Brasil. Boletim do Instituto de Pesca, São Paulo, v. 38, n. 3. p. 231-246, 2012b.

RAMIRES, M.; ROTUDO, M.M.; BEGOSSI, A. The use of fish in Ilhabela (São Paulo/Brazil): preferences, food taboos and medicinal indications. Biota Neotropica, Campinas, v. 12, n. 1, p. 21-29, 2012c. Disponível em: <http://www.biotaneotropica.org.br/v12n1/pt/abstract?article+bn00212012012>.

RAMOS, T.P.A.; ZAWADZKI, C.H.; RAMOS, R.T.C.; BRITSKI, H.A. RedescriptionofHypostomusjohnii, a seniorsynonymofHypostomuseptingi (Siluriformes: Loricariidae), NortheasternBrazil. Neotropical Ichthyology, Maringá, v. 15, n. 2, p. 1- 10. 2017.

REIS, R.E.; KULLANDER, S.O.; FERRARIS JUNIOR, C.J. Check list of the freshwater fishes of South and Central America. Porto Alegre: Edipucrs, 2003. 729 p.

REIS, R.E.; ALBERT, J.S.; DI DARIO, F.; MINCARONE, M.M.; PETRY, P.; ROCHA, L.A. Fish biodiversity and conservation in South America. Journaloffishbiology, v. 89, p. 12-47, 2016.

RODRIGUES, R.A.; MAIA, L.P. Caracterização sócio-econômica das comunidades de pescadores do município de Aquiraz-Ceará. Arquivos de Ciências do Mar, Florianópolis, v. 40, n. 1, p. 16-23, 2007.

ROSSATO, S.C.; LEITÃO-FILHO, H.F.; BEGOSSI, A. Ethnobotanyof Caiçaras oftheAtlantic Forest Coast (Brazil). EconomicBotany, New York, v. 53, n. 4, p. 387-395, 1999.

SANTOS, G.M.; MÉRONA, B.; JURAS, A.A.; JÉGU, M. Peixes do baixo Rio Tocantins: 20 anos depois da Usina Hidrelétrica Tucuruí. Brasília: Eletronorte, 2004. 215 p.

SANTOS, V.M.A.; COSTA NETO, E.M.; STRIPARI, N.L. Concepção dos pecadores artesanais que utilizam o reservatório de Furnas, Estado de Minas Gerais, acerca dos recursos pesqueiros: um estudo etnoictiológico. Biotemas, Florianópolis, v. 23, n. 4, p. 135-145, 2010.

SANTOS, K.P.P. Etnobotânica e Etnozoologia dos pescadores artesanais do município de União/PI, Brasil. 2013. 130 f. Dissertação (Mestrado em Desenvolvimento e Meio Ambiente) - Universidade Federal do Piauí, Teresina. 
Amorin et al. Entre a terra e a água: a pesca e o conhecimento etnoictiológico dos pescadores artesanais. Ethnoscientia 4, 2019. DOI: 10.22276/ethnoscientia.v4i1.240

SANTOS, K.P.P.; SOARES, R.R.; BARROS, R.F.M. Atividade pesqueira de embarcações na colônia de pescadores Z-18 do município de União/PI, Brasil. Holos, Natal, v. 6, 2015.

SANTOS, K.P.P. Etnozoologia e Etnoecologia na Comunidade de Pescadores Artesanais de Miguel Alves, PI/Brasil. 2017. 199 f. Tese (Doutorado em Desenvolvimento e Meio Ambiente) - Universidade Federal do Piaú, Teresina.

SANTOS, K.P.P.; VIEIRA, I.R.; ALENCAR, N.L.; SOARES, R.R.; BARROS, R.F.M. Percepção ambiental sobre a degradação dos recursos hídricos na comunidade de pescadores artesanais de Miguel Alves/Brasil. Educação Ambiental em Ação, São Paulo, v. 59, p. 01-12, 2017.

SANTOS, K.P.P.; VIEIRA, I.R.; ALENCAR, N.L.; SOARES, R.R.; BARROS, R.F.M. Fishingpracticesandethnoichthyologicalknowledge in thefishingcommunityof Miguel Alves, Piauí, Brazil. Boletim do Instituto de Pesca, v. 44, n. 1, p. 25-34. 2018.

SECRETARIA ESPECIAL DE AQUICULTURA E PESCA - SEAP/PR. Plano de desenvolvimento da aquicultura no Piauí. Disponível em: http://www.sebrae.com.br/Sebrae/Portal\%20Sebrae/UFs/PI/Anexos/1PLANO\%20DE\%20DESENVOLVIMENTO\%20DA\%20AQUICULTURA\%20NO\%20ESTADO\%20DO\%20PIAU \%C3\%8D.pdf. Acesso em: 24 ago. 2019.

SEDREZ, M.C.; SANTOS, C.F.; MARENZI, R.C.; SEDREZ, S.T.; BARBIERI, E.; BRANCO, J.O. Caracterização socioeconômica da pesca artesanal do camarão sete-barbas em Porto Belo, SC. Boletim do Instituto de Pesca, São Paulo, v. 39, n. 3, p. 311-322, 2013.

SILVA, J.T.; BRAGA, T.M.P. Etnoictiologia de pescadores artesanales de lacomunidad de Surucuá (Reserva Extractiva Tapajós-Arapiuns). Revista de Antropologia (Online), São Paulo, v. 9, n. 1, p. 238-257, 2017.

SILVA, T.R.; COSTA NETO, E.M.; ROCHA, S.S. Etnobiologia do caranguejo de água doce TrichodactylusfluviatilisLatreille, 1828 no povoado de Pedra Branca, Santa Teresinha, Bahia. Revista Gaia Scientia, João Pessoa, v. 8, n. 1, p. 51-64, 2014.

SILVA, V.G. O Antropólogo e sua magia. São Paulo: Edusp, 2000. 200 p.

SILVA-GONÇALVES, R.; D’INCAO, F. Perfil socioeconômico e laboral dos pescadores artesanais de camarãorosa no complexo estuarino de Tramandaí (RS), Brasil. Boletim do Instituto de Pesca, São Paulo, v. 42, n. 2 , p. 387 401, 2016.

SILVANO, R. A. M. B. Pesca artesanal e etnoictiologia. In: BEGOSSI, A. (Org.) Ecologia de pescadores da Mata Atlântica e da Amazônia. São Paulo: Hucitec/Nepam/ Unicamp, 2004. p. 187-222.

SILVANO, R.A.M.; BEGOSSI, A. Ethnoichthyology and fish conservation in the Piracicaba river (Brazil). JournalofEthnobiology, Tacoma, v. 22, n. 2, p. 285-306, 2002.

SOUSA, R. S. Etnobotânnica e etnozoologia de comunidades pesqueiras da área de proteção ambiental (APA) do Delta do Parnaíba, nordeste do Brasil. 2010. 175p. Dissertação (Mestrado em Desenvolvimento e Meio ambiente) - Universidade Federal do Piauí, Teresina.

SOUSA, D.G.; MENDES, N.C.B.; PEREIRA, L.J.G.; FERNANDES, S.C.P.; BENTES, B.S. Estrutura populacional e reprodução do Anujá, TrachelyopterusgaleatusLinnaeus, 1766), em uma área de uso sustentável da Zona Costeira Amazônica. Biota Amazônia, Macapá, v. 6, n. 2, p. 41-49, 2016.

SOUZA; AURICCHIO, (2002). In: ALBUQUERQUE, U.P.; LUCENA, R.F.P.; CUNHA L.V.F.C. Métodos e técnicas na pesquisa etnobotânica, Recife: NUPEEA, 2010. p. 312.

TARKAN, A.S.; ELMELÇI, F.G.; VILIZZI, L.; COPP, G.H. Risk screening of non-native freshwater fishes at the frontier between Asia and Europe: first application in Turkey of the fish invasiveness screening kit. Journal of Applied Ichthyology, Berlin, v. 30, n. 2, p. 392-398, 2014.

TROTTER, R.; LOGAN, M. Informant consensus: a new approach for identifying potentially effective medicinal plants.In: ETKIN, N. L. (Ed.) Indigenous medicine and diet: biobehavioural approaches. New York: Redgrave Bedford Hills, 1986. p. 91-112.

VIANA, L.F.; SANTOS, S.L.;LIMA-JUNIOR, S.E. Variação sazonal na alimentação de Pimelodella cf. gracilis (Osteichthyes, Siluriformes, Pimelodidae) no rio Amambai, Estado de Mato Grosso do Sul. Acta Scientarium. BiologicalSciences, Maringá, v. 28, n. 2, p. 123-128, 2006.

ZACARKIM, C.E.; OLOVEIRA, L.C.; DUTRA, F.M. Perfil dos pescadores da foz do rio Araguaia, Brasil. Revista Eletrônica de Extensão, Santa Catarina, v. 14, n. 25, p. 27-44, 2017. Dispinível em: <https://periodicos.ufsc.br/index.php/extensio/article/view/1807-0221.2017v14n25p27>. Acesso em: 27 dez. 2017.

ZANCHETT, S.A.S. Memória e História: Os pescadores Coxineneses e suas trajetórias de vida cotidiana. MONÇÔESRevista do curso de História/CPCX - campus da Universidade de Coxim, Coxim, v. 2, n. 2 , p 63 - 84. 2015. Disponível em: <http://seer.ufms.br/index.php/moncx/article/view/171/pdf_7>. Acesso em: 22 dez. 2017. 
Apêndice 1. Relação das espécies de peixes ocorrentes no rio Poti, na região de Castelo do Piauí, Piauí, Brasil.

\begin{tabular}{|c|c|c|c|c|c|c|c|c|c|c|c|}
\hline Ordem/Família/ Nome científico & Nome vulgar & Origem & Cat. de uso & VUg & VUa & VUp & FA & FR & IR & $\begin{array}{c}\text { Artefatos de } \\
\text { pesca }\end{array}$ & $\begin{array}{l}\mathbf{N}^{\circ} \text { de } \\
\text { coletor }\end{array}$ \\
\hline \multicolumn{12}{|l|}{$\begin{array}{l}\text { CHARACIFORMES } \\
\text { ANOSTOMIDAE }\end{array}$} \\
\hline Leporinus friderici (Bloch, 1794) & Piau-de-coco & $\mathrm{Mi}$ & $\mathrm{A} / \mathrm{C}$ & 1,78 & 1,75 & 0,04 & 47 & 6,39 & 0,40 & $\mathrm{AV} / \mathrm{AL} / \mathrm{E} / \mathrm{T}$ & 29 \\
\hline $\begin{array}{l}\text { Schizodon dissimilis (Garman, 1890) } \\
\text { BRYCONIDAE }\end{array}$ & Piau-de-vara & $\mathrm{Mi}, \mathrm{En}$ & $\mathrm{A} / \mathrm{C}$ & 1,78 & 1,75 & 0,04 & 49 & 6,66 & - & $\mathrm{AV} / \mathrm{AL} / \mathrm{E} / \mathrm{T}$ & - \\
\hline $\begin{array}{l}\text { Salminus maxillosus (Cuvier, 1816) } \\
\text { CHARACIDAE }\end{array}$ & Dourado & $\mathrm{Mi}$ & $\mathrm{A} / \mathrm{C}$ & 0,04 & 0,04 & - & 1 & 0,14 & - & $\mathrm{E} / \mathrm{T}$ & - \\
\hline $\begin{array}{l}\text { Roeboides sazimai (Lucena, 2007) } \\
\text { CHILODONTIDAE }\end{array}$ & Cacunda & Ex & $\mathrm{A} / \mathrm{M} / \mathrm{C}$ & 0,11 & 0,11 & - & 3 & 0,41 & - & $\mathrm{E} / \mathrm{T}$ & 19 \\
\hline Caenotropus labyrinthicus (Kner, 1858) & Escama-dura & SI & $\mathrm{A} / \mathrm{C}$ & 0,04 & 0,04 & - & 1 & 0,14 & - & $\mathrm{E} / \mathrm{T}$ & - \\
\hline $\begin{array}{l}\text { CURIMATIDAE } \\
\text { Curimata macrops (Eigenmann \& } \\
\text { Eigenmann, 1889) }\end{array}$ & Branquinha-do-oião * & Ex & $\mathrm{A} / \mathrm{M} / \mathrm{C}$ & 1,75 & 1,69 & 0,05 & 48 & 6,52 & 0,40 & $\mathrm{AV} / \mathrm{AL} / \mathrm{E} / \mathrm{T}$ & 42 \\
\hline Curimata sp. & Branquinha/Piaba & $\mathrm{Mi}$ & $\mathrm{A} / \mathrm{C}$ & 0,25 & 0,24 & 0,02 & 1 & 0,14 & - & $\mathrm{AV} / \mathrm{AL} / \mathrm{E} / \mathrm{T}$ & 45 \\
\hline $\begin{array}{l}\text { Psectrogaster rhomboides (Eigenmann } \\
\text { \& Eigenmann, 1889) } \\
\text { ERYTHRINIDAE }\end{array}$ & Piaba-boca-lascada & $\mathrm{Mi}$ & $\mathrm{A} / \mathrm{C}$ & 0,04 & 0,04 & & 1 & 0,14 & - & $\mathrm{E} / \mathrm{T}$ & 41 \\
\hline Hoplias aff. Malabaricus (Bloch, 1794) & Traíra * & SI & $\mathrm{A} / \mathrm{M} / \mathrm{C}$ & 1,56 & 1,35 & 0,22 & 37 & 5,03 & 1,82 & $E / G / T$ & 54 \\
\hline $\begin{array}{l}\text { Hoplerythrinus unitaeniatu (Spix \& } \\
\text { Agassiz, 1829) Aimara } \\
\text { HEMIODONTIDAE }\end{array}$ & Saboga/ Sabão & SI & $\mathrm{A} / \mathrm{C}$ & 0,07 & 0,07 & - & 2 & 0,27 & - & $\mathrm{E} / \mathrm{T}$ & - \\
\hline $\begin{array}{l}\text { Hemiodus parnaguae (Eigenmann \& } \\
\text { Henn, 1916) }\end{array}$ & $\begin{array}{l}\text { Frecheira/ Joaninha/ } \\
\text { Saúna/ Frecheirinha }\end{array}$ & En & $\mathrm{A} / \mathrm{M} / \mathrm{C}$ & 0,82 & 0,80 & 0,02 & 23 & 3,13 & 0,20 & $\mathrm{AV} / \mathrm{AL} / \mathrm{E} / \mathrm{T}$ & 37 \\
\hline $\begin{array}{l}\text { PROCHILODONTIDAE } \\
\text { Prochilodus lacustris (Steindaches } \\
\text { 1907) }\end{array}$ & Crumatá * & En, Mi & $\mathrm{A} / \mathrm{C}$ & 2,02 & 1,85 & 0,16 & 52 & 7,07 & 1,39 & $\mathrm{E} / \mathrm{T}$ & 1 \\
\hline $\begin{array}{l}\text { SERRASALMIDAE } \\
\text { Myleus asterias (Müller \& Troschel, } \\
\text { 1844) }\end{array}$ & Moeda/Pacu & $\mathrm{Mi}$ & $\mathrm{A} / \mathrm{C}$ & 0,18 & 0,18 & - & 5 & 0,68 & - & $\mathrm{E} / \mathrm{T}$ & 26 \\
\hline $\begin{array}{l}\text { Serrasalmus rhombeus (Linnaeus, } \\
\text { 1766) }\end{array}$ & Pirambeba & SI & $\mathrm{A} / \mathrm{C}$ & 1,35 & 1,35 & - & 38 & 5,16 & - & $\mathrm{E} / \mathrm{T}$ & 10 \\
\hline Pygocentrus nattereri (Kner, 1858) & Piranha-caju (vermelha) & SI & $\mathrm{A} / \mathrm{C}$ & 1,31 & 1,31 & - & 37 & 5,03 & - & $\mathrm{E} / \mathrm{T}$ & 15 \\
\hline Pygocentrus piraya (Cuvier, 1819) & Piranha-preta & SI & $\mathrm{A} / \mathrm{M} / \mathrm{C}$ & 0,40 & 0,35 & 0,05 & 8 & 1,09 & 0,75 & $\mathrm{E} / \mathrm{T}$ & - \\
\hline $\begin{array}{l}\text { Colossoma macropomum (Cuvier, } \\
1816 \text { ) }\end{array}$ & Tambaqui & Ex & $\mathrm{A} / \mathrm{M} / \mathrm{C}$ & 0,58 & 0,55 & 0,04 & 15 & 2,04 & 0,40 & $\mathrm{E} / \mathrm{T}$ & - \\
\hline
\end{tabular}

Legenda: En: endêmica; Mi: migratória; Ex: exótica; A: alimentícia; M: medicinal; C: Comercial; VUg: Valor de uso geral; VUa: Valor de uso atual; VUp: Valor de uso potencial; FA: Frequência Absoluta; FR: Frequência Relativa; IR: Importância relativa; SI: Sem informação; *: reimosa; AL: Anzol de linha; AV: Anzol de vara; E: Engancho; G: Groseira; T: Tarrafa. Cat. De uso: categoria de uso. 


\begin{tabular}{|c|c|c|c|c|c|c|c|c|c|c|c|}
\hline Ordem/Família/ Nome científico & Nome vulgar & Origem & Cat. de uso & $\mathbf{V U g}$ & VUa & VUp & FA & FR & IR & $\begin{array}{c}\text { Artefatos de } \\
\text { pesca }\end{array}$ & $\begin{array}{c}\mathrm{N}^{0} \text { de } \\
\text { coletor }\end{array}$ \\
\hline Triportheus signatus (Garman, 1890) & $\begin{array}{l}\text { Sardinha-comum/ } \\
\text { Sardinha-de-escama * }\end{array}$ & SI & $\mathrm{A} / \mathrm{M} / \mathrm{C}$ & 0,73 & 0,71 & 0,02 & 18 & 2,45 & - & $\mathrm{E} / \mathrm{T}$ & 41 \\
\hline $\begin{array}{l}\text { RHAMPHICHTHYIDAE } \\
\text { Rhamphichthys rostratus (Linnaeus, } \\
\text { 1766) } \\
\text { CYPRINIFORMES } \\
\text { CYPRINIDAE }\end{array}$ & Sarapó & SI & $\mathrm{A} / \mathrm{C}$ & 0,22 & 0,22 & - & 6 & 0,82 & - & $\mathrm{E} / \mathrm{T}$ & 5 \\
\hline $\begin{array}{l}\text { Cyprinus sp (Linnaeus, 1758) } \\
\text { GYMNOTIFORMES } \\
\text { STERNOPYGIDAE }\end{array}$ & Carpa & SI & $\mathrm{A} / \mathrm{C}$ & 0,11 & 0,11 & - & 3 & 0,41 & - & $\mathrm{E} / \mathrm{T}$ & - \\
\hline $\begin{array}{l}\text { Sternopygus macrurus (Schneider, } \\
\text { 1801) } \\
\text { MYLIOBATIFORMES } \\
\text { POTAMOTRYGONIDAE }\end{array}$ & Lamprega & SI & $\mathrm{A} / \mathrm{C}$ & 0,11 & 0,11 & - & 2 & 0,27 & - & $\mathrm{E} / \mathrm{T}$ & 44 \\
\hline Potamotrygon signata (Garman, 1913) & Arraia & En & $\mathrm{A} / \mathrm{M} / \mathrm{C}$ & 0,60 & 0,47 & 0,13 & 20 & 2,72 & 2,00 & $\mathrm{E} / \mathrm{T}$ & 51 \\
\hline $\begin{array}{l}\text { OSTEOGLOSSIFORMES } \\
\text { ARAPAIMIDAE }\end{array}$ & & & & & & & & & & & \\
\hline $\begin{array}{l}\text { Arapaima gigas }(\text { Schinz, 1822) } \\
\text { PERCIFORMES } \\
\text { CICHLIDAE }\end{array}$ & Pirarucu & SI & $\mathrm{A} / \mathrm{C}$ & 0,04 & 0,04 & - & 1 & 0,14 & - & $\mathrm{E} / \mathrm{T}$ & - \\
\hline $\begin{array}{l}\text { Geophagus parnaibae (Staeck \& } \\
\text { Schindler, 2006) }\end{array}$ & Coró & SI & $\mathrm{A} / \mathrm{C}$ & 0,38 & 0,36 & 0,02 & 10 & 1,36 & 0,20 & $\mathrm{E} / \mathrm{T}$ & 11 \\
\hline $\begin{array}{l}\text { Cichla monoculus (Spix \& Agassiz, } \\
\text { 1831) }\end{array}$ & Tucunaré * & Ex & $\mathrm{A} / \mathrm{M} / \mathrm{C}$ & 0,95 & 0,91 & 0,04 & 25 & 3,40 & 0,55 & $\mathrm{E} / \mathrm{T}$ & 22 \\
\hline Tilapia rendalli (Boulenger, 1897) & Tilápia & Ex & $\mathrm{A} / \mathrm{M} / \mathrm{C}$ & 0,38 & 0,36 & 0,02 & 20 & 2,72 & 0,20 & $\mathrm{E} / \mathrm{T}$ & - \\
\hline $\begin{array}{l}\text { SCIAENIDAE } \\
\text { Plagioscion squamosissimus (Heckel, } \\
\text { 1840) }\end{array}$ & Curvina * & SI & $\mathrm{A} / \mathrm{C}$ & 1,49 & 1,42 & 0,07 & 39 & 5,30 & 0,40 & $\mathrm{E} / \mathrm{T}$ & 7 \\
\hline $\begin{array}{l}\text { SILURIFORMES } \\
\text { AUCHENIPTERIDAE }\end{array}$ & & & & & & & & & & & \\
\hline $\begin{array}{l}\text { Trachelyopterus galeatus (Linnaeus, } \\
\text { 1766) }\end{array}$ & Barriga mole (Cumbá) & SI & $\mathrm{A} / \mathrm{C}$ & 0,22 & 0,22 & - & 6 & 0.82 & - & $\mathrm{E} / \mathrm{T}$ & - \\
\hline Ageneiosus inermis (Linnaeus, 1766) & Matrinxã & Mi & $\mathrm{A} / \mathrm{C}$ & 0,04 & 0,04 & - & 1 & 0,14 & - & $\mathrm{E} / \mathrm{T}$ & - \\
\hline Ageneiosus sp (Valenciennes, 1836) & Fidalgo & $\mathrm{Mi}$ & $\mathrm{A} / \mathrm{M} / \mathrm{C}$ & 0,07 & 0,07 & - & 2 & 0,27 & - & $\mathrm{E} / \mathrm{T}$ & - \\
\hline $\begin{array}{l}\text { Trachelyopterus galeatus (Linnaeus, } \\
\text { 1766) }\end{array}$ & Porca/serra-negra * & Mi & $\mathrm{A} / \mathrm{C}$ & 0,29 & 0,29 & - & 8 & 1,09 & - & $\mathrm{E} / \mathrm{T}$ & 13 \\
\hline
\end{tabular}

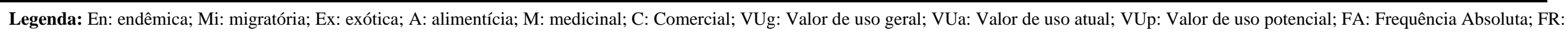
Frequência Relativa; IR: Importância relativa; SI: Sem informação; *: reimosa; AL: Anzol de linha; AV: Anzol de vara; E: Engancho; G: Groseira; T: Tarrafa. Cat. De uso: categoria de uso. 


\begin{tabular}{|c|c|c|c|c|c|c|c|c|c|c|c|}
\hline Ordem/Família/ Nome científico & Nome vulgar & Origem & Cat. de uso & VUg & VUa & VUp & FA & FR & IR & $\begin{array}{c}\text { Artefatos de } \\
\text { pesca }\end{array}$ & $\begin{array}{l}\mathbf{N}^{0} \text { de } \\
\text { coletor }\end{array}$ \\
\hline $\begin{array}{l}\text { Ageneiosus brevifilis (Valenciennes, } \\
1840 \text { ) }\end{array}$ & Mandubé * & SI & $\mathrm{A} / \mathrm{C}$ & 1,18 & 1,16 & 0,02 & 32 & 4,35 & - & $\mathrm{E} / \mathrm{T}$ & - \\
\hline $\begin{array}{l}\text { Auchenipterus menezesi Ferraris \& Vari, } \\
1999 \\
\text { LORICARIIDAE }\end{array}$ & Sardinha de couro & En & $\mathrm{A} / \mathrm{C}$ & 0,07 & 0,07 & - & 2 & 0,27 & - & $\mathrm{E} / \mathrm{T}$ & 43 \\
\hline $\begin{array}{l}\text { Hypostomus plecostomus (Linnaeus, } \\
1758 \text { ) }\end{array}$ & Cari/ Cascudo * & En & $\mathrm{A} / \mathrm{M} / \mathrm{C}$ & 1,51 & 1,44 & 0,07 & 37 & 5,03 & 0,46 & $\mathrm{E} / \mathrm{T}$ & 27 \\
\hline $\begin{array}{l}\text { Loricaria parnahybae (Steindachnner, } \\
\text { 1907) }\end{array}$ & Cari cachimbo & En & $\mathrm{A} / \mathrm{C}$ & 0,04 & 0,04 & - & 1 & 0,14 & - & $\mathrm{E} / \mathrm{T}$ & 23 \\
\hline $\begin{array}{l}\text { Pterygoplichthys joselimaianus (Weber, } \\
\text { 1991). }\end{array}$ & $\begin{array}{l}\text { Cari-boi-pintado (Carro- } \\
\text { de-boi) }\end{array}$ & SI & $\mathrm{A} / \mathrm{M} / \mathrm{C}$ & 0,11 & 0,11 & - & 2 & 0,27 & 0,46 & $\mathrm{E} / \mathrm{T}$ & 46 \\
\hline Gymnotus carapo (Linnaeus, 1758) & Cari-pequeno/ Cará & SI & $\mathrm{A} / \mathrm{M} / \mathrm{C}$ & 0,07 & 0,07 & - & 2 & 0,27 & - & $\mathrm{E} / \mathrm{T}$ & 2 \\
\hline $\begin{array}{l}\text { Pterygoplichthys pardalis (Castelnau, } \\
1855)\end{array}$ & Cari/Bodó & SI & $\mathrm{A} / \mathrm{C}$ & 1,51 & 1,44 & 0,07 & 12 & 1,63 & 0,46 & $\mathrm{E} / \mathrm{T}$ & 47 \\
\hline Hypostomus sp & Boi-de-carga & SI & $\mathrm{A} / \mathrm{M} / \mathrm{C}$ & 0,07 & 0,07 & - & 2 & 0.27 & 0.46 & $\mathrm{E} / \mathrm{T}$ & - \\
\hline $\begin{array}{l}\text { MOCHOKIDAE } \\
\text { Synodontis clarias (Linnaeus, 1758) }\end{array}$ & $\begin{array}{l}\text { Mandi-dourado (Boca- } \\
\text { larga, Cabeça-de-burro) }\end{array}$ & $\mathrm{Mi}$ & $\mathrm{A} / \mathrm{C}$ & 0,18 & 0,18 & - & 4 & - & - & $\mathrm{E} / \mathrm{T}$ & 3 \\
\hline $\begin{array}{l}\text { PIMELODIDAE } \\
\text { Sorubim lima (Bloch \& Schneider, } \\
\text { 1801) }\end{array}$ & Bico-de-pato * & Mi & $\mathrm{A} / \mathrm{M} / \mathrm{C}$ & 0,51 & 0,51 & - & 14 & 1,90 & - & $\mathrm{E} / \mathrm{G} / \mathrm{T}$ & 32 \\
\hline Pimelodus maculatus (Lacepède, 1803) & $\begin{array}{l}\text { Mandi-boca-de-flor (Bico- } \\
\text { fino) }\end{array}$ & Mi & $\mathrm{A} / \mathrm{C}$ & 0,04 & 0,04 & - & 1 & 0,14 & - & $\mathrm{E} / \mathrm{T}$ & 38 \\
\hline Pimelodus sp & Mandi-pintado & Mi & $\mathrm{A} / \mathrm{C}$ & 0,11 & 0,11 & - & 2 & 0,27 & - & $\mathrm{E} / \mathrm{T}$ & - \\
\hline $\begin{array}{l}\text { Pseudoplatystoma fasciatum (Linnaeus, } \\
1766 \text { ) }\end{array}$ & Surubim * & $\mathrm{Mi}$ & $\mathrm{A} / \mathrm{M} / \mathrm{C}$ & 1,69 & 1,67 & 0,02 & 46 & 6,25 & 0,20 & $\mathrm{E} / \mathrm{G} / \mathrm{T}$ & - \\
\hline Pimelodus sp & Mandi * & SI & $\mathrm{A} / \mathrm{C}$ & 1,27 & 1,27 & - & 35 & 4,76 & - & $\mathrm{AV} / \mathrm{AL} / \mathrm{E} / \mathrm{T}$ & 39 \\
\hline \multirow[t]{3}{*}{ Não identificada } & $\begin{array}{l}\text { Piaba-dourada/ Piaba- } \\
\text { gorda/ Piaba-medalha }\end{array}$ & SI & $\mathrm{A} / \mathrm{C}$ & - & - & - & 9 & 1,22 & - & $\mathrm{E} / \mathrm{T}$ & 53 \\
\hline & Piaba sul & SI & $\mathrm{A} / \mathrm{M} / \mathrm{C}$ & - & - & - & 3 & 0,41 & - & $\mathrm{E} / \mathrm{T}$ & - \\
\hline & Piau dourado & SI & $\mathrm{A} / \mathrm{C}$ & - & - & - & 1 & 0,14 & - & $\mathrm{E} / \mathrm{T}$ & - \\
\hline
\end{tabular}

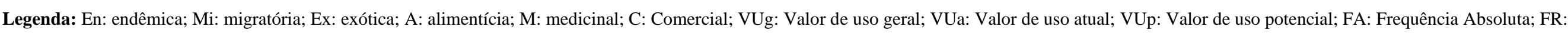
Frequência Relativa; IR: Importância relativa; SI: Sem informação; *: reimosa; AL: Anzol de linha; AV: Anzol de vara; E: Engancho; G: Groseira; T: Tarrafa. Cat. De uso: categoria de uso. 